\title{
AUTISMO E MERCADO DE TRABALHO: A PERCEPÇÃO DO AUTISTA SOBRE SUAS COMPETÊNCIAS PROFISSIONAIS
}

\section{AUTISM AND THE LABOR MARKET: THE PERCEPTION OF AUTISTIC ABOUT THEIR PROFESSIONAL SKILLS}

\author{
Hozana Teixeira Bidart \\ Universidade Federal Rural do Rio de Janeiro - UFRRJ \\ hozanabidart@hotmail.com \\ Cynthia Adrielle da Silva Santos \\ Pontifícia Universidade Católica do Rio de Janeiro PUC-Rio \\ Programa de Mestrado e Doutorado do Departamento de Administração/IAG \\ cynthia.assantos@gmail.com
}

Submissão: 01/04/2021

Aprovação: 08/11/2021

\section{RESUMO}

Indivíduos autistas encontram mais dificuldades em conseguir ou manter-se em empregos do que pessoas com outras deficiências. Apesar do quantitativo de estudos baseados em crianças, é importante refletir sobre o envelhecimento desses indivíduos e suas necessidades como adultos, a fim de integrá-los a uma vida independente. Dentro desse cenário, o objetivo desta pesquisa é entender a percepção do autista sobre como suas competências profissionais específicas podem ser incentivadas para contribuir para as organizações. Através de uma abordagem qualitativa foram realizadas doze entrevistas com pessoas diagnosticadas autistas e, por meio da análise de conteúdo, foram identificadas características específicas relacionadas ao foco nas atividades que são realizadas, como: atenção aos detalhes, empenho, pouca distração e entusiasmo por aprender. Os entrevistados ressaltaram que seria benéfico para a organização um feedback ou uma avaliação de desempenho, a fim de compreender o perfil de cada profissional, pois a partir disso será possível a estimulação do hiperfoco para fins benéficos às atividades laborais ou o direcionamento para outro setor dentro da organização, para que sejam aproveitadas suas características com mais efetividade. Também foi possível observar a importância da empresa conhecer as necessidades específicas e as características individuais dos funcionários, para evitar julgamento, preconceitos e sobrecargas, bem como a realização de adaptações no ambiente de trabalho.

Palavras-chave: Autismo. Transtorno do Espectro Autista. Competências profissionais. Mercado de Trabalho. Inclusão.

\begin{abstract}
Autistic individuals find it more difficult to get or keep jobs than people with other disabilities. Despite the number of studies based on children, it is important to reflect on the aging of these individuals and their needs as adults, in order to integrate them into an independent life. Within this scenario, the objective of this research is to understand the perception of the autistic person about how their specific professional skills can be encouraged to contribute to organizations.
\end{abstract}


Through a qualitative approach, twelve interviews were conducted with people diagnosed with autism and, through content analysis, specific characteristics related to the focus on the activities that were carried out were identified, such as: attention to details, commitment, little distraction and enthusiasm for learning. The interviewees emphasized that it would be beneficial for the organization to provide feedback or a performance evaluation, in order to understand the profile of each professional, since from this it will be possible to stimulate hyperfocus for purposes beneficial to work activities or to move to another sector. Within the organization, so that its characteristics can be used more effectively. It was also possible to observe the importance of the company knowing the specific needs and individual characteristics of employees, to avoid judgment, prejudice and overload, as well as making adaptations in the work environment.

Keywords: Autism. Autism Spectrum Disorder. Professional skills. Labor market. Inclusion.

\section{Introdução}

O Transtorno do Espectro Autista (TEA), de acordo com o Manual de Diagnóstico e Estatístico dos Transtornos Mentais (DSM), trata-se de uma classe de condições de neurodesenvolvimento caracterizada por dificuldades de interação social e comunicação não-verbal e, comportamentos estereotipados e repetitivos. Ainda de acordo com o manual, os Transtornos do Neurodesenvolvimento tratam-se de condições que ocorrem no início do período de desenvolvimento e são caracterizados por déficits nesta fase, resultando no prejuízo do funcionamento pessoal, social, acadêmico ou profissional. Esses déficits podem causar limitações específicas na aprendizagem, no controle de funções executivas, habilidades sociais ou inteligência (APA, 2013). Leopoldino et al. (2020) reforçam que as dificuldades para a inserção de profissionais autistas no mercado de trabalho ocorrem não apenas pelas limitações desses indivíduos, mas por restrições estruturais e culturais, que ocasionam a diminuição de oportunidades. Os autores ressaltam que tais obstáculos demonstram que, para parte da sociedade, pessoas com deficiência podem ser consumidoras, mas não produtoras de bens e serviços. Apesar disso, jovens autistas possuem grandes aspirações sobre suas realizações como adultos e muitos deles possuem o desejo de trabalhar, sendo esta uma parcela importante de suas expectativas pessoais (KIRBY et al., 2019).

De acordo com o DSM-V, frequentemente ocorre mais de um transtorno do neurodesenvolvimento nos indivíduos, por exemplo, indivíduos autistas podem possuir deficiência intelectual. Conforme o manual, o Transtorno do Desenvolvimento Intelectual (TDI) caracterizase por déficits funcionais, tanto intelectuais, quanto adaptativos. Além disso, para o diagnóstico do TDI é necessário que o início dos déficits ocorra durante o período do desenvolvimento. $\mathrm{O}$ DSM-V prevê que é possível ocorrer demais diagnósticos concomitantes ao autismo, por exemplo, transtorno de déficit de atenção/hiperatividade (TDAH), transtorno do desenvolvimento da coordenação, transtornos de ansiedade, transtornos depressivos, entre outros. Ainda, pessoas diagnosticadas no espectro autista podem apresentar outras condições médicas, são elas: epilepsia, distúrbios do sono e constipação. O transtorno alimentar restritivo/evitativo apresentase com frequência e podem persistir preferências alimentares extremas e reduzidas (APA, 2013).

Hull et al. (2017) identificaram que indivíduos no espectro autista, ao longo da vida, podem aprender a mascarar suas características por mecanismos compensatórios, por eles chamado de masking, como uma camuflagem que visa ocultar condições do espectro autista, criando personagens em situações sociais que se distinguem de seus comportamentos verdadeiros e automáticos. Isso porque, para os profissionais autistas, ao buscarem empregos e qualificações, as oportunidades eram menos acessíveis quando suas características de autistas eram mais 
visíveis. Como consequência desse mascaramento, surge a sensação de exaustão, sendo essa uma prática mental e fisicamente desgastante, uma vez que exige concentração intensa, autocontrole e controle do desconforto. Após o masking, as pessoas no espectro precisam de tempo para se recuperar, ficando sozinhas e liberando os comportamentos suprimidos (HULL et al., 2017).

O emprego é uma atividade socialmente normativa que usualmente ocupa a maior parte da vida adulta dos indivíduos e é um componente importante para essa passagem, sendo as contribuições salariais geradoras de bem-estar econômico e social, os quais estão vinculados a resultados positivos de saúde e qualidade de vida (ROUX et al., 2013). Porém, para autistas, há necessidade de suporte e dificuldade em encontrar e manter empregos (WEHMAN et al., 2012). Devido às dificuldades para pessoas com deficiências (PCDs) em adentrarem ao mercado de trabalho, foi criada a Lei $n^{\circ} 8.213$, de 24 de julho de 1991, a chamada Lei de Cotas, que prevê uma porcentagem entre $2 \%$ a $5 \%$ dos cargos à beneficiários reabilitados ou pessoas com deficiência (BRASIL, 1991). No entanto, somente a partir de 2012, por meio da Lei $n^{\circ} 12.764$, de 27 de dezembro de 2012, as pessoas no espectro autista foram legalmente incluídas na definição de pessoas com deficiência no Brasil (BRASIL, 2012).

O DSM-V define a incidência de três níveis de suporte, com base na necessidade de apoio, considerando a comunicação social e comportamentos restritos e repetitivos, sendo incluídos no nível 3 aqueles que precisam de muito apoio, no nível 2 aqueles que necessitam de apoio substancial e no nível 1 aqueles que exigem algum nível de apoio (APA, 2013). O termo "Transtorno do Espectro Autista" descreve sua manifestação de forma heterogênea, a incidência de diferentes graus de acometimento e a interconexão de diversas condições das quais não podem ser definidas com clareza a partir de rótulos diagnósticos (KLIN, 2006). Para que empregadores e empregados estejam mais aptos a trabalhar e apoiar profissionais autistas é necessário que as diversidades e os motivos de seus comportamentos sejam compreendidos (CHAPPEL; SOMERS, 2010; HENDRICKS, 2010; SCHALL, 2010).

Em vista disso, é importante que os profissionais se atentem para as características específicas de cada indivíduo, de acordo com sua necessidade de suporte, a fim de realizar ações efetivas para sua inclusão na empresa. Tendo em vista que os indivíduos no espectro autista apresentam aptidões e habilidades únicas, é necessário que empregadores trabalhem junto ao setor de Gestão de Pessoas para delimitar o perfil comportamental deles. Um estudo dos pontos fortes e fracos, assim como de seus interesses específicos, permite inserir o profissional em uma função mais apropriada. Ademais, a combinação cuidadosa entre o indivíduo, ambiente de trabalho e suporte adequado pode resultar no seu sucesso dentro do meio empresarial (CHAPPEL; SOMERS, 2010; HENDRICKS, 2010; SCHALL, 2010; WEHMAN et al., 2012).

As pesquisas para compreender o autismo são recentes e, em grande parte, realizadas a partir de observações dos sinais em crianças, por se tratar de um transtorno de neurodesenvolvimento. No entanto, é importante reconhecer o local de fala do adulto no espectro autista, pois a partir das suas experiências é possível compreender os impactos das suas características em sua rotina e no convívio social. Um conjunto de pesquisadores tentam mapear especificamente os obstáculos enfrentados para a inclusão dos profissionais autistas no mercado de trabalho, como a carência de capacitação profissional, preparo dos funcionários autistas e da efetividade da lei de cotas, assim como ausência de suporte e adaptação no ambiente de trabalho (RAPPAPORT, 1987; MAWHOOD; HOWLIN, 1999; WAREHAM; SONNE, 2008; ROSQVIST; KEISU, 2012; ORSMOND et al., 2013; DOS ANJOS et al., 2016; SEAMAN; CANNELLAMALONE, 2016; LEOPOLDINO; COELHO, 2017).

Desse modo, este artigo pode contribuir, do ponto de vista teórico, para o aprofundamento dessas pesquisas sobre a inclusão dos profissionais autistas no mercado de trabalho ao fornecer resultados que advém da perspectiva dos próprios autistas por meio da compreensão das dificuldades e facilidades encontradas por eles ao adentrar o mercado de trabalho. Do ponto 
de vista prático, uma vez que o autista possui dificuldades na socialização, este estudo poderá ser utilizado como base de informações para que as equipes de trabalho encontrem mecanismos para conhecer e desenvolver características do profissional autista. Posto isso, considerando o cenário apresentado, o objetivo desse artigo foi entender a percepção do autista sobre como suas competências profissionais específicas podem ser incentivadas para contribuir para as organizações. Para tanto, o artigo está estruturado com a fundamentação teórica, seguida pelas seções de procedimentos metodológicos, análise dos resultados e, por fim, considerações finais.

\section{Inclusão Social e Identidade da Pessoa com Deficiência (PCD)}

Ao analisar historicamente a relação de convivência entre pessoas com deficiência e os demais, pode-se observar um explícito preconceito, tendo em vista que são tratadas de maneira diferente, seja como empecilhos, seja como divindades (FONSECA, 1997). O preconceito e a discriminação no tratamento adotado por pessoas sem deficiência (PSDs) com relação às pessoas com deficiência (PCDs), conhecido como capacitismo, é conceituado por Dias (2013, p. 6) como "a concepção presente no social que lê as pessoas com deficiência como não iguais, menos aptas ou não capazes para gerir as próprias vidas".

Por esses motivos, foram criadas leis de suporte e inclusão, como a Lei n ${ }^{\circ} 12.764$, de 27 de dezembro de 2012, instituindo a Política Nacional de Proteção dos Direitos das Pessoas com TEA, e a Lei Brasileira de Inclusão da Pessoa com Deficiência, Lei n 13.146, de 6 de julho de 2015, destinada a assegurar e promover, em condições de igualdade, os direitos e as liberdades fundamentais para pessoas com deficiência. Além disso, o Decreto $\mathrm{n}^{\circ} 9.508$, de 24 de setembro de 2018, prevê o percentual de cargos ofertados às pessoas com deficiência no âmbito da administração pública. Juntos, os normativos asseguram legalmente os direitos de pessoas com deficiência à inclusão social e cidadania (BRASIL, 1991, 2012, 2015, 2018).

$\mathrm{O}$ autismo se manifesta de forma heterogênea e possui diferentes graus de acometimento, sendo assim, originou-se o termo Transtorno do Espectro do Autismo (TEA) (KLIN, 2006). Segundo a quinta edição do DSM-V ${ }^{1}$, pessoas diagnosticadas no transtorno do espectro autista costumam apresentar prejuízo persistente na comunicação social recíproca e na interação social, como padrões repetitivos e/ou restritos de comportamento, interesses ou atividades, déficits na reciprocidade socioemocional, linguagem unilateral ou nula, dificuldades de processamento e resposta para pistas sociais complexas. Com relação aos déficits em comportamentos de comunicação não verbal, possuem contato visual reduzido, ausente ou atípico e apresentam dificuldade de utilizar gestos expressivos e espontâneos na comunicação (APA, 2013).

Além disso, podem apresentar estereotipias motoras, uso repetitivo de objetos, fala repetitiva, resistência às mudanças e padrões ritualizados de comportamento verbal ou não verbal. Possuem interesses altamente limitados e fixos e hiper ou hiporreatividade a estímulos sensoriais, por exemplo, a sons, texturas, cheiros, luzes, objetos giratórios e, algumas vezes, aparente indiferença a dor, calor ou frio. Para que o indivíduo com as características citadas receba o devido diagnóstico, deve ocorrer o prejuízo significativo no âmbito social, profissional ou em outras áreas importantes da vida do indivíduo no presente. O DSM-V define o TEA em três graus, de acordo com a necessidade de apoio, sendo: nível 3 aqueles que precisam de muito apoio, nível 2 aqueles que necessitam de apoio substancial e nível 1 para os que exigem algum apoio (APA, 2013).

Criado pela Organização Mundial da Saúde (OMS), outro manual comumente utilizado é a Classificação Estatística Internacional de Doenças e Problemas Relacionados com a Saúde

\footnotetext{
${ }^{1}$ Segundo a APA (2013), o DSM se propõe a ser um guia prático, funcional e flexível, visando organizar informações que possam auxiliar no diagnóstico preciso e no tratamento de transtornos mentais. Ao longo dos últimos 60 anos, o documento passou por sucessivas atualizações e tornou-se uma referência para a prática clínica na área da saúde mental.
} 
(CID). Atualmente, utiliza-se a CID-10 ${ }^{2}$. No entanto, a CID-11 está prevista para começar a vigorar em 2022. A CID-10 difere diversos diagnósticos dentro do grupo "Transtornos Invasivos do Desenvolvimento (F84)", caracterizado por anormalidades qualitativas de reciprocidade em interação social e em padrões de comunicação e por interesses e atividades restritas, estereotipadas e repetitivas. No entanto, a nova versão do documento reúne todos os diagnósticos em Transtorno do Espectro do Autismo (WHO, 1992).

Pessoas autistas podem apresentar hiperfocos que se tratam de situações em que direcionam atenção ou estímulos extremamente seletivos (LOVAAS et al., 1971). O incentivo aos interesses específicos durante a infância e adolescência de indivíduos autistas, permite a escolha de carreiras relacionadas a estes, aumentando a qualidade do seu trabalho, estudo e sua satisfação pessoal. Assim, será possível um melhor aproveitamento de seus pontos fortes e provavelmente a demonstração de mais habilidades sociais, comunicativas, emocionais, sensoriais e executivas no contexto do emprego (WINTER-MESSIERS et al., 2007; APA, 2013).

\section{Autismo e Mercado de Trabalho}

Nos últimos anos, tem ocorrido uma crescente quantidade de literatura sobre o autismo, além das legislações criarem mecanismos facilitadores para a popularização do sistema de inclusão. Apesar do quantitativo de estudos baseados em crianças, é importante refletir sobre envelhecimento desses indivíduos e suas necessidades como adultos, a fim de integrá-los a uma vida independente (PARR; HUNTER, 2013). O Instituto Nacional de Estudos e Pesquisas Educacionais Anísio Teixeira (INEP) apontou no Censo da Educação Superior dos últimos anos um crescimento na inclusão de pessoas diagnosticadas no espectro do autismo nas universidades e faculdades brasileiras. Com base nas classificações estabelecidas pelo DSM-V, em 2015 foram identificados 442 ingressantes autistas nas universidades, enquanto em 2018 foram identificados 1.357 (APA, 2013; INEP, 2019). Através da inclusão de autistas na academia e na formação profissional, poderão se extinguir estigmas de pessoas incapazes e antissociais, assim como retirá-los da invisibilidade (SALES; VIANA, 2020).

Para os autistas, a inclusão no mercado de trabalho demonstrou retornos variados para o profissional, como independência financeira e pessoal, melhora nas relações sociais, trabalho em equipe, comunicação, solução de problemas, sensação de propósito e reabilitação cognitiva. Também foram observados resultados positivos na relação familiar, tendo em vista a diminuição da sobrecarga emocional e o aumento da qualidade de vida (HILLIER et al., 2007; GARCÍA-VILLAMISAR; HUGHES, 2007; MCSTAY et al., 2013; GOMES et al., 2015; HEDLEY et al., 2017). Entretanto, poucas empresas procuram auxílio para contratar pessoas com deficiência em escolas ou instituições especializadas, muitas vezes recorrendo a agências convencionais de emprego (ARAUJO; SCHMIDT, 2006). Quando empregados, indivíduos autistas trabalham menos horas e recebem salários mais baixos do que pessoas com outras deficiências (CIMERA; COWAN, 2009), e ainda são constantemente subestimados e sua construção baseada predominantemente em características negativas que torna invisíveis seus atributos positivos.

Para as empresas, essa contratação pode ser benéfica ao aproveitar as habilidades do profissional autista em atividades específicas, por exemplo, a capacidade de se concentrar, atenção aos detalhes e realização de atividades repetitivas. De modo geral, deve-se avaliar os fatores associados a contratação de profissionais autistas a partir da perspectiva desses profissionais e dos indivíduos que trabalham com eles. São características facilitadoras para o sucesso de autistas no local de trabalho: um relacionamento com a equipe de trabalho, apoio da liderança e

\footnotetext{
${ }^{2}$ A CID-10 foi estruturada para ser uma classificação central em uma gama de classificações relacionadas às doenças e à saúde. Publicada pela Organização Mundial de Saúde (OMS), é composta por descrições clínicas e diretrizes diagnósticas (WHO, 1992).
} 
de colegas, permissão para modificações laborais no ambiente e a presença de um consultor. Como desafios, têm-se dificuldades relacionadas às tarefas, fatores individuais e dificuldades sociais (HEDLEY et al., 2017; DREAVER et al., 2019). Um estudo realizado por Hurlbutt e Chalmers (2004) apontou que um fator importante para o sucesso do profissional autista no mercado de trabalho é a descrição das normas, expectativas, deveres e responsabilidades esperados para o profissional, pois assim torna-se possível compreender o que é esperado deles, referente à sua produtividade, tipo de tarefas e regras.

Tendo em vista que o autismo e suas características são marginalizados, ocorre preconceito de potenciais empregadores e discriminação de colegas, sendo as dificuldades com relação à consciência social prejudicada mais comuns do que os problemas relacionados às demandas do trabalho. Além disso, trabalhadores com autismo não têm possibilidade de crescimento nas organizações, quando estas não acreditam em suas potencialidades (WAREHAM; SONNE, 2008; ROSQVIST; KEISU, 2012; DOS ANJOS et al.; SEAMAN; CANNELLA-MALONE, 2016; LEOPOLDINO; COELHO, 2017). De acordo com Sassaki (1997), organizações podem realizar determinadas medidas para integrar o profissional com deficiência, por exemplo, a realização de seminários e reuniões de sensibilização e inclusão do trabalhador com deficiência em planos de promoção na carreira. Além disso, Lattimore et al. (2003) concluem que autistas se envolvem mais nas tarefas quando combinadas com seus interesses. Ao compreender características de pessoas autistas como oportunidades ao invés de fraquezas (ROSQVIST; KEISU, 2012) e seu conjunto de habilidades distintas, a contratação de profissionais no espectro pode fornecer à organização uma vantagem competitiva (RAPPAPORT, 1987; PARR; HUNTER, 2013).

\section{Competências Profissionais da Pessoa Autista}

A gestão por competências trata-se do instrumento para planejar, captar, desenvolver e avaliar as competências individuais, grupais e organizacionais necessárias para alcançar os objetivos da organização, por meio da seleção de profissionais adequados a cada cargo, formulação de treinamentos ou tomada de decisões estratégicas (VILAS BOAS; ANDRADE, 2009; CARBONE et al., 2009). Na literatura encontram-se disponíveis alguns conceitos do termo "competências", por exemplo, "um saber agir responsável e reconhecido, que implica mobilizar, integrar, transferir conhecimentos, recursos e habilidades, que agreguem valor econômico à organização e valor social ao indivíduo" (FLEURY; FLEURY, 2001, p.188).

Para Boyatzis (1982), a competência é uma característica implícita do indivíduo, sendo ela um traço, habilidade, conhecimento, motivo ou aspecto da própria imagem ou papel social, não necessariamente de maneira consciente. Para o autor, uma ação ou um comportamento específico trata-se de uma competência quando se refere às demandas e requisitos do ambiente organizacional. Por fim, Parry (1996) definiu competência como o conjunto de conhecimentos, habilidades e atitudes (CHA), relacionados à performance, que podem ser melhorados a partir de treinamentos. Maluf (2014) acrescentou à sigla a entrega (CHAE), sendo essa caracterizada pela capacidade de atender o esperado pelas organizações.

Indivíduos no espectro autista possuem uma gama de habilidades e motivações distintas, além de pontos fortes que os tornam excelentes funcionários (AUSTIN; SONNE, 2014). Apesar de alguns indivíduos autistas, geralmente com menor necessidade de suporte, conseguirem encontrar emprego sem auxílio e decidirem manter em segredo sua deficiência, na maioria dos casos os empregadores percebem algumas dificuldades, embora possam não compreender totalmente quais (HOWLIN, 2004). Existe uma ampla variação de talentos em pessoas autistas com relação ao restante da população, como: capacidade de concentração, competência, confiabilidade, eficiência, honestidade, rigorosa adesão às regras, excelente memória, senso de observação, facilidade em autocorreção, atenção aos detalhes e preferência por tarefas repetitivas e que demandem foco, além da motivação para finalizar demandas (HOWLIN, 2004; HILLIER 
et al., 2007; WAREHAM; SONNE, 2008; ARMSTRONG, 2010, 2012; SCHALL; WEHMAN; MCDONOUGH, 2012).

Pessoas autistas possuem facilidade em seguir regras e manter rotinas, devido a sua rigidez e dificuldade com coisas novas, tornando-os mais assíduos e pontuais, além de apresentarem senso de lealdade a ambientes de trabalho que lhe oferecem suporte (HURLBUTT; CHALMERS, 2004; HOWLIN, 2004; SCHALL; WEHMAN; MCDONOUGH, 2012; APA, 2013; LEOPOLDINO, 2015). Segundo os autores, autistas preferem ambientes silenciosos e costumam não perder tempo com ligações pessoais e conversas paralelas, contribuindo para maior produtividade e precisão no trabalho realizado. Pessoas autistas costumam preferir ambientes visualmente organizados e trabalham bem com máquinas, computadores, mapas, horários e outros sistemas, bem como, ao aprenderem uma tarefa, apresentam alta taxa de precisão para realizá-la.

No geral, considerar o ambiente de trabalho do ponto de vista dos funcionários pode fornecer aos gerentes uma ferramenta de grande impacto para muitas partes da organização (AUSTIN; SONNE, 2014). Pessoas autistas são particularmente sensíveis a aspectos sutis desse ambiente que podem ocasionar seu sucesso ou fazer com que deixem o emprego mais cedo (SCHALL; WEHMAN; MCDONOUGH, 2012). O estudo de Dreaver et al. (2019) demonstrou a importância da adaptação do ambiente de trabalho como um fator essencial para determinar sua adequação. Segundo os autores, por meio do conhecimento das necessidades do profissional autista, as características do local foram flexibilizadas, com a diminuição de ruídos, luzes e movimentos, além da oportunidade de uma pausa e a flexibilização nas rotinas de trabalho. Isso porque, é importante que as instruções aos funcionários autistas sejam apresentadas visualmente ou escritas. No tocante às dificuldades em se comunicar, tendo em vista a dificuldade de indivíduos autistas em captar dicas sutis, é necessário que sejam realizados feedbacks de forma direta sobre seu desempenho (HOWLIN, 2004).

\section{Procedimentos Metodológicos}

Para a realização dessa pesquisa, foi utilizada uma abordagem qualitativa, uma vez que esta descreve de forma rica e fundamentada o assunto abordado, além de captar explicações sobre processos em contextos específicos, auxiliando o pesquisador a avançar junto às concepções iniciais ou revisar sua estrutura teórica (VIEIRA; ZOUAIN, 2004). Assim, foi realizada uma pesquisa de campo, selecionando um grupo de trabalhadores autistas que puderam definir com clareza suas percepções com relação ao impacto de suas características especificas para a organização a qual estão inseridos.

Para a coleta de dados o método escolhido foi a entrevista, uma vez que, de acordo com Rosa e Arnoldi (2006), esta é uma técnica que reflete uma discussão orientada para um objetivo definido, que através do questionamento, incentiva o respondente a discorrer com base em suas percepções sobre temas específicos. Severino (2007) acrescenta que por meio da entrevista é possível compreender o que os respondentes pensam, sabem, representam, fazem e argumentam. Dessa maneira, foi utilizado um roteiro semi-estruturado para a realização de entrevistas individuais, com questões abertas, conforme disposto em Apêndice. Esse modelo de roteiro foi escolhido, visto que Laville e Dionne (1999, p. 188) o definem como uma "série de perguntas abertas, feitas verbalmente em uma ordem prevista, mas na qual o entrevistador pode acrescentar perguntas de esclarecimento".

As pesquisadoras realizaram contato através de grupos de apoio na rede social Facebook, direcionados a membros diagnosticados autistas, em busca deste diagnóstico ou simpatizantes da causa, foram eles: "Vida no Espectro (Grupo de Autistas)", com 1.045 membros, "\{ Mulheres Autistas BR \}", com 961 membros, "Aspielândia", com 781 membros e "Pergunte para um autista", com 2.506 membros. Além disso, também foi realizado contato através da rede social Instagram, com pessoas ativistas pela causa autista. 
Seguindo esses pressupostos e tendo em vista que a pesquisa ocorreu em um contexto de pandemia mundial do COVID-19, as entrevistas foram realizadas em mídias interativas, onde foi questionado aos interessados o meio mais viável à sua realização, e foram escolhidos os aplicativos: Messenger, WhatsApp, Instagram, Zoom, StreamYard e Google Meets. Em média, as entrevistas duraram 40 minutos e alguns participantes preferiram sua realização por meio de textos e áudios, enquanto outros preferiram chamadas de videoconferência. As entrevistas ocorreram no período de 28 de setembro a 11 de novembro de 2020.

Para a elaboração desta pesquisa, foram escolhidas pessoas com diagnóstico em Transtorno do Espectro Autista, de acordo com o DSM-V, ou outras classificações equivalentes, constantes na CID-10, diagnosticadas por profissional formado em medicina, todas maiores de 18 anos, que já se encontram no mercado de trabalho e residem no território brasileiro. Todos os entrevistados receberam o Termo de Consentimento Livre e Esclarecido e concordaram com as informações dispostas neste.

As respostas das entrevistas realizadas foram transcritas e analisadas minuciosamente, com a finalidade de preservar sua integridade. Para facilitar a compreensão dos dados e apresentação das informações optou-se pela técnica de análise de conteúdo em todo o processo. Segundo Bardin (1977) esse método pode ser definido como um conjunto de técnicas de análise das comunicações visando obter indicadores, quantitativos ou não, que permitam a conclusão de conhecimentos relativos às condições de produção dessas mensagens, através de procedimentos sistemáticos e objetivos de descrição do seu conteúdo.

Segundo Vergara (2005, p. 18) "categorizar implica isolar elementos para, em seguida, agrupá-los". Bardin (1977) define a categorização como rubricas ou classes que reúnem um grupo de componentes sob um título genérico, em razão dos caracteres comuns destes elementos. O autor ressalta que o processo de classificação é consideravelmente importante em toda atividade científica. Para tanto, foi elaborado o Quadro 1, utilizando o embasamento teórico para alcançar o objetivo da pesquisa.

Quadro 1: Categorização das análises

\begin{tabular}{|c|c|}
\hline Categoria & Operacionalização \\
\hline Caracterização do entrevistado & $\begin{array}{l}\text { - } \quad \text { Perfil dos trabalhadores; } \\
\text { - } \quad \text { Como eles reconhecem a sua identidade como profissional autista; } \\
\text { - } \quad \text { Com qual idade foram diagnosticados; } \\
\text { - } \quad \text { Sentimento de inclusão; e } \\
\text { - } \quad \text { Nível de suporte. }\end{array}$ \\
\hline Percurso profissional & $\begin{array}{l}\text { - } \quad \text { Informações sobre capacitação profissional; } \\
\text { - } \quad \text { Barreiras enfrentadas até entrar no mercado de trabalho; } \\
\text { - } \quad \text { Se ocorreram situações de preconceito em entrevistas profissionais; } \\
\text { - } \quad \text { Forma de ingresso no emprego (através do sistema de cotas ou não); } \\
\text { - } \quad \text { Se a empresa possui ciência do diagnóstico de autismo; } \\
\text { - } \quad \text { Impressão sobre a possibilidade de crescimento profissional; } \\
\text { - } \quad \text { Carga horária semanal; e } \\
\text { - } \quad \text { Forma de ingresso no emprego atual. }\end{array}$ \\
\hline Rotina de trabalho & $\begin{array}{l}\text { - Identificação do cargo dos trabalhadores; } \\
\text { - Tempo de serviço no emprego atual; } \\
\text { - } \quad \text { Instrumentos que ajudaram a atingir os objetivos no trabalho; e } \\
\text { - } \quad \text { Dificuldades e desafios no local de trabalho. }\end{array}$ \\
\hline $\begin{array}{l}\text { Impacto dos interesses específicos } \\
\text { no desempenho profissional }\end{array}$ & $\begin{array}{l}\text { - } \quad \text { Identificação da relação que o profissional possui com seus interes- } \\
\text { - } \quad \text { Pes específicos; e } \\
\text { dos interescesão dos profissionais autistas sobre seus pontos fortes acerca } \\
\text { dosicos. }\end{array}$ \\
\hline Adaptação do ambiente de trabalho & $\begin{array}{l}\text { - Necessidade de adaptações no ambiente de serviço ou na rotina de } \\
\text { trabalho; } \\
\text { - } \quad \text { Sentimento de lealdade com relação à empresa; }\end{array}$ \\
\hline
\end{tabular}




\begin{tabular}{|c|c|}
\hline & $\begin{array}{l}\text { - Influência das possíveis e/ou existentes adaptações na qualidade do } \\
\text { serviço; } \\
\text { - } \quad \text { Percepção sobre as distrações no ambiente de trabalho; e } \\
\text { - } \quad \text { Existência e efetividade de feedbacks realizados. }\end{array}$ \\
\hline $\begin{array}{l}\text { Relação interpessoal no ambiente de } \\
\text { trabaho }\end{array}$ & $\begin{array}{l}\text { - } \quad \text { Relação com a figura de liderança; } \\
\text { - } \quad \text { Relação com os demais colegas de trabalho; } \\
\text { - } \quad \text { Percepção sobre a distração com o aparelho celular no ambiente de } \\
\text { trabalho; } \\
\text { - } \quad \text { Distração com conversas paralelas junto aos colegas de trabalho du- } \\
\text { - } \quad \text { Fante o expediente; e } \\
\end{array}$ \\
\hline $\begin{array}{l}\text { Competências profissionais com } \\
\text { base em suas características pessoais } \\
\text { e específicas de indivíduos no espe- } \\
\text { tro autista }\end{array}$ & $\begin{array}{l}\text { - Percepção se as características pessoais específicas agregam no de- } \\
\text { sempenho do trabalho; } \\
\text { - Percepção se as características pessoais específicas influenciam ne- } \\
\text { gativamente no desempenho do trabalho; } \\
\text { - Aproveitamento da empresa sobre as competências características } \\
\text { do autismo. }\end{array}$ \\
\hline $\begin{array}{l}\text { Padrão de competências profissio- } \\
\text { nais com base em características pes- } \\
\text { soais e específicas de indivíduos no } \\
\text { espectro autista }\end{array}$ & $\begin{array}{l}\text { - Características específicas comparadas com o padrão disponível na } \\
\text { - } \quad \text { Percepção das características pessoais específicas como contribui- } \\
\text { ção para as organizações. }\end{array}$ \\
\hline $\begin{array}{l}\text { Percepção sobre como as competên- } \\
\text { cias profissionais específicas podem } \\
\text { ser incentivadas para contribuir para } \\
\quad \text { as organizações }\end{array}$ & $\begin{array}{l}\text { - Percepção sobre como as competências profissionais específicas po- } \\
\text { dem ser incentivadas para contribuir para a empresa. }\end{array}$ \\
\hline
\end{tabular}

Fonte: Elaborado pelas autoras (2020).

\section{Análise de Resultados}

Nesta seção, são apresentados os resultados da pesquisa, abarcando as nove categorias criadas, nas seguintes subseções: (6.1) Caracterização dos entrevistados; (6.2) Percurso profissional; (6.3) Rotina de trabalho; (6.4) Impacto dos interesses específicos no desempenho profissional; (6.5) Adaptação do ambiente de trabalho; (6.6) Relação interpessoal no ambiente de trabalho; (6.7) Competências profissionais com base em características pessoais e específicas; (6.8) Padrão disponível na literatura de competências profissionais com base em características pessoais e específicas de indivíduos no espectro autista e; (6.9) Percepção sobre como as competências profissionais específicas podem ser incentivadas para contribuir para as organizações.

\subsection{Caracterização dos entrevistados}

Foram entrevistados doze indivíduos autistas, tendo sido definida uma numeração para identificar cada participante, a fim de preservar suas identidades. Estão dispostas no Quadro 2 as informações de cada um, a partir das questões respondidas nas entrevistas. 


\section{Quadro 2: Informações dos participantes}

\begin{tabular}{|c|c|c|c|c|c|c|c|}
\hline $\begin{array}{c}\text { Parti- } \\
\text { cipante }\end{array}$ & Idade & $\begin{array}{l}\text { Idade ao re- } \\
\text { ceber o di- } \\
\text { agnóstico }\end{array}$ & $\begin{array}{l}\text { Gênero } \\
\text { que se } \\
\text { identifica }\end{array}$ & $\begin{array}{l}\text { Cidade/Estado de } \\
\text { residência }\end{array}$ & Formação & Ramo da empresa & Profissão/Cargo \\
\hline 1 & 39 & 38 & Feminino & Brasília/DF & - Bacharel em Arquivologia. & Mercado financeiro & Analista de Arquivologia \\
\hline 2 & 27 & 25 & Feminino & Itaquaquecetuba/SP & $\begin{array}{l}\text { - Graduação em Psicologia; e } \\
\text { - Pós-graduação em Transtorno do Espectro Autista. }\end{array}$ & Organização não-governamental & Psicóloga \\
\hline 3 & 31 & 20 & Masculino & São Paulo/SP & • Ensino médio completo. & Limpeza e conservação & Auxiliar administrativo \\
\hline 4 & 24 & 23 & Feminino & Charqueadas/RS & • Graduação em Fisioterapia. & Hospital & Fisioterapeuta \\
\hline 5 & 31 & 30 & Feminino & Nova Friburgo/RJ & $\begin{array}{l}\text { - Ensino médio completo com formação de professores; e } \\
\text { - Curso técnico de enfermagem. }\end{array}$ & Creche & Auxiliar de Creche \\
\hline 6 & 28 & 27 & Feminino & Jequié/BA & $\begin{array}{l}\text { - Técnico em Informática; e Enfermagem; } \\
\text { - Graduação em Negócios familiares; e } \\
\text { - Atualmente é graduanda em Computação e Licenciatura. }\end{array}$ & Escola & Técnica de informática \\
\hline 7 & 57 & 57 & Feminino & Rio de Janeiro/RJ & $\begin{array}{l}\text { - Graduação em Física; } \\
\text { - Mestrado em Biofísica; e } \\
\text { - Doutorado em Biofísica. }\end{array}$ & Universidade & Professora e Pesquisadora \\
\hline 8 & 42 & $\begin{array}{l}\text { Na faixa dos } \\
30 \text { anos }\end{array}$ & Masculino & Campo Grande/MS & $\begin{array}{l}\text { - Graduação em: Administração; Pedagogia; Serviço So- } \\
\text { cial; Gestão de RH; e História; } \\
\text { - Pós-graduação em: Gestão de Pessoas; Educação à Dis- } \\
\text { tância e Tecnologias Educacionais; Autismo e Transtornos } \\
\text { do desenvolvimento; Neurociência; e Neuropsicopedago- } \\
\text { gia Clínica e Institucional; } \\
\text { - MBA em Gestão de Pessoas; } \\
\text { - Mestrado em Administração; } \\
\text { - Doutorado em Ciências da Educação; e } \\
\text { - Cursando Doutorado em Educação Especial e Inclusiva } \\
\text { em Autismo. }\end{array}$ & Universidade & Pesquisador \\
\hline 9 & 29 & 27 & Feminino & Campinas/SP & $\begin{array}{l}\text { - Curso de formação técnica específica na Academia de } \\
\text { Polícia; e } \\
\text { - Cursando graduação em Psicologia. }\end{array}$ & Polícia Civil & Agente policial \\
\hline 10 & 29 & 27 & Neutro & Brasília/DF & • Graduação em Psicologia. & Clínica de Psicologia & Psicóloga clínica \\
\hline 11 & 31 & 25 & Masculino & Dores do Turvo/MG & $\begin{array}{l}\text { - Graduação em Ciência e Tecnologia de Alimentos; e } \\
\text { - Licenciatura em: Letras-Inglês; e Química. }\end{array}$ & Escola & Professor de Química \\
\hline 12 & 31 & 31 & Feminino & São Paulo/SP & $\begin{array}{l}\text { - Graduação em: Educação artística; e Pedagogia; } \\
\text { - Pós-graduação em Arteterapia; } \\
\text { - Cursando graduação em Psicologia; e } \\
\text { - Cursando pós-graduação em Educação inclusiva com ên- } \\
\text { fase em Transtornos Globais do desenvolvimento e altas } \\
\text { habilidades. }\end{array}$ & Escola & Professora de Artes \\
\hline
\end{tabular}

Fonte: elaborado pelas autoras (2020). 
Dos participantes, oito se identificaram com o gênero feminino, três com o gênero masculino e um com gênero neutro ${ }^{3}$. Em todos os casos, foi relatado o diagnóstico na idade adulta, indo ao encontro com Lowinger e Pearlman-Avnion (2019) que descrevem o diagnóstico na idade adulta como mais frequente do que é relatado, apesar do autismo se tratar de um transtorno do neurodesenvolvimento. Todos os participantes obtiveram seu diagnóstico na fase adulta e os relatos expressam as dificuldades enfrentadas até recebê-lo, seja por camuflar o comportamento ou pela falta de compreensão sobre sua individualidade e suas dificuldades. Ao serem questionados sobre seu nível de suporte, todos os participantes se caracterizam como nível 1 (exigindo algum nível de apoio), de acordo com o DSM-V e, apesar desse manual informar que indivíduos autistas comumente possuem deficiência intelectual, nenhum dos participantes informou apresentar esse diagnóstico. Ao serem questionados sobre o que mudou em sua identificação individual ao descobrir que está no espectro autista, as respostas foram variadas. No entanto, destaca-se a compreensão sobre suas especificidades como uma resposta predominante entre os discursos.

“(...) foi muito libertador para mim quando eu recebi o diagnóstico de... De autismo. Eu não me senti triste, pelo contrário, eu me senti muito bem e muito feliz. Eu me senti como se eu tivesse me encontrado naquele momento. (...) Na identificação individual eu comecei a me sentir menos culpada por questões que eu nunca consegui dar conta e que eu achava que eram por preguiça ou que eu achava que era uma incapacidade minha e que as outras pessoas também achavam (...)” (participante 12).

Como observado acima, a participante 12 retrata o sentimento de libertação que teve ao receber o autismo por sentir-se menos culpada por enfrentar questões que julgava ser incapacidade.

\subsection{Percurso profissional}

A listagem das formações dos participantes pode ser verificada no Quadro 2, em que é possível compreender o percurso acadêmico de cada um. Dos 12 participantes, apenas dois não ingressaram no ensino superior. Dos outros 10 participantes que cursaram ou estão cursando o ensino superior, quatro possuem mais de uma graduação. Além disso, quatro participantes possuem pelo menos uma atividade de pós-graduação, sendo dois destes doutorados. Apesar do exposto por Wareham e Sonne (2008), sobre a falta de preparação e capacitação dos funcionários autistas para o mercado de trabalho atrapalhar a contratação de pessoas autistas, pode-se perceber, através dos resultados apresentados, que os participantes da pesquisa se especializaram em suas áreas de interesse.

Ao procurar emprego, nove dos participantes responderam não informar que são autistas, sendo oito destes devido ao diagnóstico recente e não possuir o laudo à época da procura pelo emprego. Já a participante 4 informou a opção pessoal por não falar, com medo de sofrer capacitismo na área de saúde e acreditar que não receberia oportunidades. Dois dos entrevistados, os participantes 3 e 5, responderam que, ao procurar emprego, informam que são autistas. O participante 3 , ainda, informou buscar vagas específicas para pessoas com deficiência. Ao serem questionados se já sofreram algum preconceito por isso, o participante 3 informou não ter sofrido. Já a participante 5, informou que:

\footnotetext{
"Acho que [sofri] mais desinformação. Meio que invalidando meu diagnóstico e minha história. Do tipo: 'Você é muito inteligente e eficiente, não parece autista. Tem certeza sobre isso?' Acho que por ser nível [1] de suporte (...), minhas dificuldades são ignoradas” (participante 5).
}

\footnotetext{
${ }^{3}$ Lung e Ricco (2017) definem o termo gênero neutro como aquele que designa uma pessoa sem utilizar os termos masculino e feminino.
} 
Ao questionarmos sobre as barreiras enfrentadas até a entrada no mercado de trabalho, três entrevistados informaram não enfrentar barreiras. $\mathrm{O}$ participante 3 justificou sua resposta da seguinte forma:

"Então, barreiras, barreiras eu diria que não. Mas as dificuldades que eu sempre tive é que eu não tenho o dom da conquista, sabe? Eu não consigo convencer o entrevistador (...) Então essa é a minha dificuldade, tanto é que eu já fiz diversas entrevistas e a maioria das entrevistas que eu fiz na vida eu fui reprovado" (participante 3).

Os demais relataram as barreiras enfrentadas por eles nesse ingresso, predominando a dificuldade de socialização, como descritas abaixo:

"Socialização. Eu tinha muita dificuldade (ainda tenho) em socializar e no mercado de trabalho você precisa socializar e se comunicar com as pessoas. Eu nunca tive muita paciência para relações baseadas em 'moeda de troca'. Em ter que ser simpática apenas para conseguir algo em troca. Não sei se estou conseguindo me fazer entender" (participante 5).

"Sofri muito bullying, desde criança. E já na faculdade, eu não conseguia assistir aulas com muita gente, então ia para a biblioteca estudar. Fiz pouquíssimos amigos. Não ia a nenhuma festa. No mestrado, não queriam me deixar entrar, porque eu "não era compativel com o que se esperava de um pesquisador", mas como eu tirei a maior nota, tiveram que me engolir" (participante 7).

Dos doze entrevistados, cinco deles encontraram emprego através de concurso público, enquanto cinco entraram nas empresas por indicação de familiares, conhecidos ou amigos. Um dos respondentes encontrou por meio de instituições de apoio a pessoas com deficiência, enquanto outro encontrou ao demonstrar suas habilidades em um serviço freelancer. Apenas um dos entrevistados está inserido na Lei de Cotas pela empresa em que trabalha.

Quando questionados se divulgaram o diagnóstico em autismo para a empresa e demais colegas, apenas uma participante informou não divulgar o diagnóstico na organização em que trabalha. Os demais participantes informaram que o chefe sabe, porém a informação foi divulgada apenas para alguns colegas e, quando questionados sobre os motivos que os levaram a não divulgar, os motivos foram diversos. A participante 6 descreveu da seguinte forma:

"É porque, assim, eu ainda acho que têm muitas desinformações assim (...) eu sinto que falta um pouco de empatia. As pessoas falam tanto que nós autistas não temos empatia, mas eu acho que as pessoas, às vezes, não têm nenhuma empatia (...)” (participante 6).

Apesar do argumento dado por Leopoldino e Coelho (2015), de que profissionais autistas não têm possibilidade de crescimento profissional quando as organizações não acreditam em seu potencial, ao questionarmos sobre a possibilidade de crescimento profissional dos participantes, seis dos entrevistados confirmaram essa possibilidade dentro da organização em que trabalham atualmente. Dos seis restantes, três informaram que não existe esta possibilidade, visto que estão em cargos públicos dos quais não é possível essa previsão ou pela estabilidade do cargo atual com a experiência profissional. Sendo assim, apenas três dos entrevistados informaram não possuir possibilidade de crescimento, com argumentos diferentes dos mencionadas anteriormente. De todo modo, não foi apresentada como justificativa a impossibilidade de crescimento profissional devido ao fato de os participantes serem autistas.

Em contrapartida com o exposto por Leopoldino e Coelho (2015), como fatores que dificultam o ingresso de profissionais autistas no mercado de trabalho, com relação à carga horária semanal, os participantes em sua maioria, disseram não possuir carga horária reduzida ou específica. Dos participantes, cinco informaram trabalhar entre 30 e 39 horas semanais e três 
participantes informaram trabalhar mais de 40 horas semanais. Destas, duas participantes informaram também trabalhar em regime de plantão. Dos demais participantes, foi informado que trabalham na empresa atual entre 20 e 25 horas semanais.

\subsection{Rotina de trabalho}

A literatura aponta benefícios da contratação de profissionais autistas no mercado de trabalho no setor de tecnologia, tendo em vista sua extrema atenção aos detalhes, ótima memória e sistemática capacidade de concentração no trabalho (WAREHAM; SONNE, 2008; COSTA; NAKANDAKARE; PAULINO, 2018). No entanto, conforme verificado no Quadro 2 , é possível destacar o variado acervo de profissões e cargos dos participantes desta pesquisa. Em vista disso, é importante considerar que o autismo se manifesta de forma heterogênea, sendo a interconexão de diversas condições das quais não podem ser definidas com clareza a partir de rótulos diagnósticos (KLIN, 2006). As características já mencionadas poderão ser aproveitadas por outros ramos empresariais, de acordo com o interesse e identificação dos profissionais autistas.

Quando questionados se trabalham com outras pessoas autistas ou com outras deficiências, cinco participantes informaram trabalhar com outras pessoas com deficiência. No entanto, apenas um dos participantes informou trabalhar com outra profissional autista. Os demais responderam não trabalhar com pessoas autistas ou com outras deficiências. Com relação às características que ajudaram os participantes a atingir os objetivos no trabalho atual, as respostas foram variadas. Dentre elas, pode-se destacar a liberdade oferecida pelos superiores e o hiperfoco.

“Liberdade. Liberdade. Er... Os meus superiores, 'né’?! Eles me dão muita liberdade para eu poder trabalhar da forma como eu acho que é o correto e eles me dão liberdade para 'tá conversando com eles, 'pra' gente estar sempre discutindo a melhor solução para tudo. Então eles me dão realmente essa liberdade, tanto 'pra' comunicação, quanto 'pra' execução”' (participante 11).

"Olha, no trabalho da investigação de homicídio eu acredito que tem muitas características que ajudam. Err... Principalmente o hiperfoco 'pra' investigação, porque às vezes eu sento na minha mesa e eu trabalho 12 horas direto, se deixar... Err... E a questão de conseguir dissociar a parte emocional (...)" (participante 9).

Quando questionados sobre os desafios e dificuldades no local de trabalho, identificamos como barreiras as questões sensoriais no ambiente de trabalho, dificuldades em enfrentar mudanças e a sensação de incompreensão das pessoas, aliada à dificuldade de compreensão de sinais não-verbais. Sendo essas características comuns a pessoas no espectro autista, além do capacitismo dos demais colegas de trabalho. Essas questões relacionam-se com o exposto por Wing (1998), Dias (2013) e APA (2013).

"Os congressos. Ter que participar de congressos ou reuniões cientificas. É muita gente falando ao mesmo tempo. Eu fico exausta. Às vezes, vou para o quarto do hotel chorar de desespero. Algumas vezes deixei de ir, por achar que não iria aguentar" (participante 7).

"Er... Eu creio que é a aceitação das pessoas, acreditarem no potencial que eu tenho. Não ficarem duvidando. E também não ficarem me tratando de forma infantilizada. Porque as pessoas costumam tratar a pessoa com autismo de forma infantilizada. : E isso é péssimo" (participante 8).

A partir dos relatos é possível perceber que não apenas a dificuldade pessoal de socialização dos profissionais autistas com os colegas é um obstáculo, sendo a dificuldade de comunicação dos colegas com os profissionais autistas uma barreira importante no mercado de trabalho. Quando os profissionais enfrentam as situações acima, as sensações foram descritas como exaustão, dificuldade de regulação própria e sensação de detonação. 


\subsection{Impacto dos interesses específicos no desempenho profissional}

Quando questionados se possuem interesses específicos, todos os participantes informaram possuir, o que se alinha ao exposto por Lovaas et al. (1971), em que pessoas autistas podem apresentar hiperfocos, ou seja, situações extremamente seletivas em que direcionam sua atenção ou seus estímulos (WINTER-MESSIERS et al., 2007; APA, 2013). Alguns participantes descreveram a forma que os interesses específicos se relacionam com as atividades que realizam em seus empregos.

\footnotetext{
"Cara, eu escutei uma vez de um psicólogo que eu comecei a passar lá atrás, que o meu hiperfoco era curiosidade, no geral, assim, e eu acho que isso é o que melhor me define, de fato, nesse ponto. Er... Então, 'pra' área de trabalho, eu fui 'pra' uma área, assim, de investigação, que eu descobri, porque de uns tempos atrás, que eu gosto tanto das investigações de homicídios. (...) Então o que me fascina, o que me move é essa curiosidade de entender a motivação do crime, de reconstruir isso e acredito que essa questão da reconstrução de processos é uma coisa que eu levo não só no trabalho, não só na polícia, mas também na questão acadêmica" (participante 9).

“(...) uma coisa também que sempre me chamou muita atenção e eu gosto é dar aulas diferentes, então poder pegar qualquer material caseiro e demonstrar reações químicas ou explicar alguma parte da matéria teórica de uma forma prática, com o que os alunos têm casa er... É o que eu tento fazer e eu sempre tenho um foco nisso, então eu busco vídeos no YouTube... Eu tento elaborar meu próprio material, ser criativo, é uma coisa muito minha mesmo" (participante 11).
}

Através dos resultados é possível concluir que interesses específicos dos profissionais autistas se relacionam diretamente com as atividades realizadas por eles na escolha de seus empregos e traz benefícios diretos às atividades que executam, principalmente porque seus hiperfocos são relacionados aos estudos e aprendizados. Além disso, possuem impacto fundamental em suas vidas, como hobbies e possibilidade de independência. Essa visão é apoiada por Lattimore et al. (2003), que afirmam que quando associados os interesses específicos às atividades do seu trabalho, auxilia no envolvimento com as atividades executadas. Posto isso, é de suma importância que as organizações desenvolvam programas e projetos que observem características autísticas no momento da contratação, visando auxiliar o processo de inclusão.

\subsection{Adaptação do ambiente de trabalho}

Com relação às adaptações no ambiente de trabalho, segundo Dreaver (2019), trata-se de um fator essencial para a adequação do autista ao trabalho. Quatro participantes informaram obter adaptações em seu ambiente de trabalho, enquanto sete não possuem e um não soube responder. Dos participantes em que a organização não realizou adaptações no ambiente de trabalho, três informaram não julgar necessária qualquer adaptação. Daqueles que veem necessidade de adaptação, as respostas foram variadas. O participante 8 informou que a empresa "poderia, pelo menos, ter me disponibilizado um protetor auricular". Já a participante 4:

\footnotetext{
"Algumas adaptações na parte administrativa do meu trabalho. Nesse hospital, as evoluções dos prontuários são feitas à mão. E eu não gosto de escrever. Então demoro muito, se fosse no computador, seria melhor" (participante 4).
}

Dos quatro participantes em que a organização realizou adaptações no ambiente de trabalho, dois acreditam que as adaptações causam lealdade à empresa, enquanto outros dois não acreditam. Essas afirmativas estão relacionadas ao descrito por Leopoldino (2015), que profissionais autistas possuem mais lealdade a ambientes de trabalho que ofereçam suporte. No entanto, ao analisar as respostas apresentadas, pode-se dizer que essa característica varia de profissional para profissional e não sendo uma regra. A participante 10 respondeu que "não exatamente, mas achei muito gentil a iniciativa e preocupação com o meu bem-estar". A participante 9, que não acredita que as mudanças causem lealdade à empresa, respondeu: "Não. Na verdade, 
não. A única coisa que me mantém no meu trabalho é o fato de eu gostar muito do que eu faço e de eu não ter uma empresa concorrente, porque o funcionalismo público em São Paulo é bem dificil”."

Com relação às adaptações realizadas, para a participante 10 , a empresa realizou a troca do relógio de ponteiro por um digital, devido ao seu incômodo. No entanto, negou sua adaptação quanto ao local de alimentação, como pode ser observado no relato a seguir:

"Colocou um relógio digital, porque eu disse que me incomodo muito com o barulho do relógio de ponteiro. Eu queria poder comer em outro ambiente para não ter que esperar todos comerem, mas não permitiram. Nas salas já haviam cortinas, então me poupou de ter que fazer essa solicitação para fazer o controle da intensidade da luz. Acho que poderiam ser mais flexíveis para permitir almoçar em outro local" (participante 10).

Foi informado pelo participante 1 que a empresa o possibilitou "trabalhar em um local mais isolado, sem muito barulho, com uma estação de trabalho para mim”. Já a participante 6 informou que a empresa ofereceu à ela a possibilidade de se ausentar, a carga horária de trabalho reduzida, possibilidade de não utilizar o telefone e de utilizar os fones de ouvido durante o expediente de trabalho. Além disso, ressaltou outras medidas que a empresa realizou por ela durante a pandemia do COVID-19, como trabalhar em casa enquanto outros colaboradores trabalham presencialmente, a redução ainda maior da carga horária e a atenção do coordenador para que a participante não se sobrecarregue com as atividades que executa no trabalho. A participante 9 também descreveu as adaptações realizadas, como por trabalhar em uma delegacia especializada possui uma rotina menos rígida e a possibilidade de trabalhar em um horário alternativo se estiver sobrecarregada, no que a participante chama de "ressaca social".

“Então, é que hoje eu trabalho em uma delegacia especializada, 'né'?! Então a minha rotina... Ela é um pouco menos rígida, porque eu trabalho mais por demanda, do que por... Por horário, 'né'?! E eu tenho essa flexibilidade, de se eu não estou bem em um dia, não ir, ou de trabalhar num horário alternativo, se eu tiver, por exemplo, com uma ressaca social, hoje dentro do departamento, 'né'?! Da divisão em que eu trabalho, eu tenho isso, amanhã ou depois, se eu mudar de divisão, é possível... É bem provável, na verdade, que eu não tenha mais” (participante 9).

Quando questionamos aos quatro participantes que obtiveram adaptações da empresa sobre a influência delas na qualidade de seus serviços, as respostas foram variadas. A participante 1 informou que "melhora muita coisa: eu fico menos distraída, eu tenho mais espaço, não tenho barulho". A participante 6 informou que "é muito grande, assim, a qualidade". Já as participantes 9 e 10 responderam que as mudanças ajudaram a diminuir a quantidade de crises e a diminuir a ansiedade no trabalho.

"Elas são necessárias 'pra' diminuir a minha quantidade de crise, o que está diretamente atrelado a minha... Er... Ao meu nível de ansiedade, elas são bem importantes, na verdade” (participante 9).

"Melhorou muito. O barulho do relógio me deixava irritada, então eu tirava da parede e colocava em outro lugar e tinha que ficar olhando a hora no celular toda hora para não ter atrasos nos atendimentos. Dessa forma, eu trabalho até menos ansiosa, sem a preocupação de olhar as horas no celular toda hora" (participante 10).

Com relação às distrações no ambiente de trabalho, questionamos quais situações desencadeavam uma distração, como cada participante lida com isso e quanto tempo leva para se recuperar. Foi possível identificar como situações que os distraem as conversas paralelas, brigas, celular apitando e falar sobre autismo. Quando questionado como lida com isso e quanto tempo demora para se recuperar, o participante 3 informou que tenta controlar o máximo e que se recupera rapidamente. Já a participante 4 descreveu as distrações encontradas na UTI em que 
trabalha, por exemplo, os alarmes que monitoram os pacientes, pois são muitos alarmes simultâneos dentro do quarto. Para lidar com isso, ela informou se concentrar e terminar o mais rápido possível, além de pedir ajuda aos técnicos com relação aos alarmes que apenas apitam quando existem problemas técnicos.

Em vista disso, a participante 4 informou: "e $u$ não tenho muito tempo para me recuperar para ir para outro paciente. Eu fico sobrecarregada e me recupero só em casa". A participante 7 descreveu que costuma se concentrar nas tarefas de trabalho de modo que quando as pessoas falam com ela, costuma não lembrar o que respondeu e isso lhe causa problemas. Já o participante 8 informou que se distrai com "conversas paralelas não relacionadas ao trabalho" e, para lidar com isso, informa que: "Eu fico um pouco irritado. Sair do ambiente, me acalmar um pouco e voltar. E quando não dá eu coloco o protetor auricular (...)”. Ao ser questionado sobre quanto tempo leva para se recuperar respondeu que precisa sair um pouco.

Howlin (2004) descreve a importância da realização de um feedback direto e honesto sobre o desempenho dos profissionais autistas, devido à dificuldade de comunicação e ao captar dicas sutis. Sendo assim, foi questionado se os superiores realizam feedbacks com os participantes e se, sim, se são efetivos para a melhora do desempenho. Sete participantes informaram que recebem feedback na empresa em que trabalham. Destes, seis acreditam que seja efetivo para a melhora de seu desempenho, enquanto um dos participantes não soube responder à pergunta.

\subsection{Relação interpessoal no ambiente de trabalho}

De acordo com Parr e Hunter (2013), a relação interpessoal no ambiente de trabalho é importante para adaptação do profissional autista à empresa, com ênfase na figura de liderança. Segundo os autores, é recomendado que os líderes demonstrem apoio e consideração para que os funcionários se sintam envolvidos com a organização. Em vista disso, foi questionado sobre a relação dos participantes com o superior direto, a fim de identificar como acontece essa socialização dentro do ambiente de trabalho. O participante 1 informou que a relação é muito boa e que se sente acolhido pelo seu superior.

"Meu relacionamento é muito bom, tenho muita facilidade com trocas e o ponto positivo é que ele é extremamente acolhedor. Ele me apoia em tudo. Se eu tenho dificuldades, ele vai lá me dá força” (participante 1).

Já a participante 2, informa que a relação apesar de boa, é complexa, devido ao fato de que ambas são autistas. Por isso, às vezes ocorrem problemas de comunicação.

"Nossa relação é boa, mas ao mesmo tempo complexa. É uma via de mão dupla de conveniências. Como ela também é autista e ela é grau 2, nem sempre entende algumas coisas e acabamos discutindo por isso. Me dá aval 'pra' fazer o que quiser desde que ela ciente” (participante 2).

Levando em consideração que pessoas autistas possuem mais dificuldade de fazer amizades ou de serem convidados para atividades (ORSMOND et al., 2013) também foi questionado sobre a relação com os demais colegas de trabalho e, de modo geral, foi possível observar que as relações são amigáveis dentro do ambiente de trabalho e os colegas costumam apoiá-los. É importante destacar, ainda, a resposta do participante 8, que informou não possuir qualquer relação com seus colegas de trabalho, caracterizando os colegas como "apenas pessoas que trabalham comigo". Além disso, é importante ressaltar a dificuldade dos profissionais em lidar com as questões com relação às interações sociais, tendo cada participante aprendido a melhor forma de realizá-las, quando necessário. Já as participantes 6 e 7 reforçam que possuem muita dificuldade de socialização com os colegas de trabalho, principalmente com relação às confraternizações. 
Tendo em vista o apontado por Hurlbutt e Chalmers (2004), que pessoas autistas não costumam perder tempo com ligações pessoais e conversas paralelas durante o expediente de trabalho, foi identificado que oito dos participantes não costumam se distrair com chamadas em seu celular ou com a utilização de redes sociais durante o expediente de trabalho e que oito participantes costumam ter conversas paralelas com seus colegas de trabalho durante o expediente. Além disso, onze dos participantes possuem facilidade para pedir ajuda quando não compreendem algo sobre suas tarefas, enquanto apenas um dos entrevistados informou que depende, justificando que "se for 'pra' alguém de confiança eu pergunto de boa, mas se for 'pra' alguém que me deixa ansiosa eu evito e acabo fazendo errado ou deixando de fazer" (participante 5).

\subsection{Competências profissionais com base em características pessoais e específicas}

Austin e Sonne (2014) descrevem que indivíduos autistas possuem uma variedade de habilidades distintas, assim como pontos fortes que os torna excelentes funcionários. Em vista disso, foi questionado aos participantes se acreditam que possuem características específicas que agregam no desempenho profissional, a fim de compreender se as características pessoais e específicas dos profissionais autistas podem ser consideradas competências profissionais. Dentre as respostas recepcionadas, identificamos a "capacidade de fazer poucas pausas e de ser detalhista" (participante 1), "o empenho, "né’?! Em fazer bem feito" (participante 3) e "hiperfoco em organização, minha disciplina com rotina e regras" (participante 5). Também descreveram o hiperfoco os participantes $4,6,9,11$ e 12 . O participante 8 informou que possui superdotação aliada ao autismo e QI acima da média. Já a participante 7 citou outras competências profissionais, como atenção, foco e visão diferenciada. Apenas uma das participantes informou não possuir competências profissionais relacionadas ao autismo que agreguem no seu desempenho em seu emprego atual, conforme o relato abaixo:

\footnotetext{
"Não, inclusive acredito que meu emprego vai todo contra as questões autísticas. Tem bastante barulho (das crianças, bastante grito), tudo acontece muito rápido e em sequência, às vezes sem tempo 'pra' fazer xixi, lido com pessoas o tempo todo" (participante 2).
}

Também foi questionado se os participantes acreditam possuir características específicas relacionadas ao autismo que influenciem negativamente o seu desempenho profissional. Os participantes 1 e 3 informaram que possuem dificuldade com relação à impulsividade e ausência de filtros sociais. A participante 7 e o participante 11 informaram como influências negativas a "falta de sociabilidade e a literalidade". Também descreveram a falta de sociabilidade os participantes 8 e 12, enquanto a participante 12 descreveu também questões sensoriais. As participantes 4, 5 e 6 descreveram a dificuldade com relação às sobrecargas, no caso da participante 5 , com relação à "hipersensibilidade auditiva e com luz". A participante 4 com relação à sensibilidade auditiva e ao toque. Já a participante 6 com relação à sensibilidade olfativa. A participante 9 destacou a rigidez como sendo uma característica que influência negativamente em seu desempenho.

Um dos participantes ressaltou que são características que influenciam negativamente o seu desempenho a "interação social, principalmente, a dificuldade com mudança de rotina, coisas imprevisíveis, algumas reações a certos estímulos sensoriais" (participante 10). Apenas a participante 2 informou que não possui características que influenciam negativamente, somente a questão da sobrecarga por questões auditivas, porém ela consegue relevar. Dos participantes da pesquisa, dez acreditam que suas características relacionadas ao autismo estão sendo bem aproveitadas. O participante 8 informou que não está, pois, segundo ele "poderia ser bem mais aproveitada. Eu 'tô' num serviço... Operacional. É... Como se fala... Tipo um tapa-buraco". Já a participante 12 informou que "mais ou menos". Além disso, a participante 5 descreveu que as características estão sendo bem aproveitadas devido ao fato de serem "trabalhos que exigem foco, organização, disciplina e compromisso". 
6.8 Padrão disponível na literatura de competências profissionais com base em características pessoais e específicas de indivíduos no espectro autista

Foi realizado um comparativo do padrão disponível na literatura com as características pessoais e específicas dos participantes da pesquisa. Todos os participantes responderam que se consideram concentrados ao realizar suas tarefas, possuem forte atenção para detalhes, interesse por tarefas repetitivas e que demandem foco, completam todas as atividades que lhe são demandadas, preferem ambientes visualmente organizados e realizam suas tarefas com precisão. O gráfico 1 descreve a quantidade de participantes que informaram possuir boa memória, facilidade em autocorreção, pontualidade, assiduidade, preferência por uma rotina no ambiente de trabalho e que seguem rigorosamente às regras.

Gráfico 1 - Características com base no padrão disponível na literatura

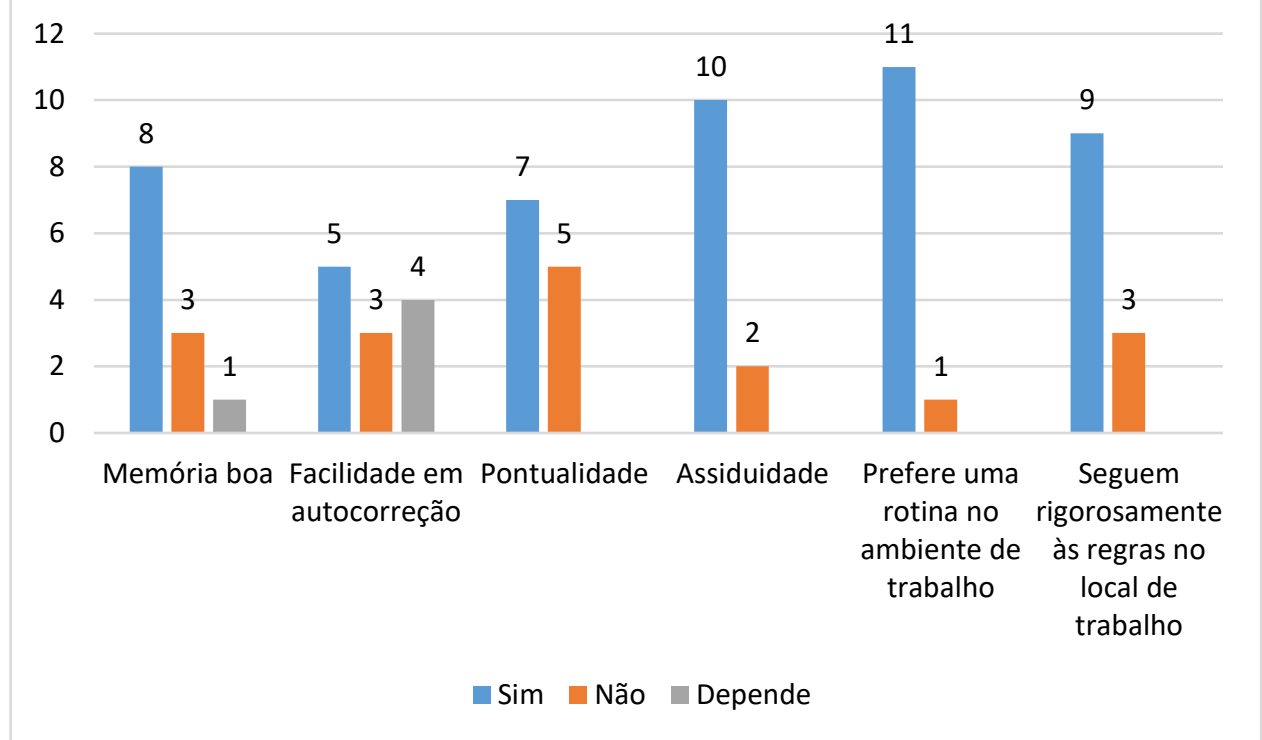

Fonte: Elaborado pelas autoras (2020).

Enquanto metade dos participantes prefere que suas tarefas sejam repassadas a eles de forma escrita, a outra metade de participantes divide-se em: três preferem que seja de forma falada, duas preferem que seja de ambas as formas e um depende da pessoa que irá repassá-las. As justificativas foram diversas, a participante 1 informou que depende da pessoa, pois algumas pessoas não são específicas em suas solicitações. Já com relação às duas participantes que informaram que preferem de ambas as formas, a participante 6 informou que precisa que as informações sejam passadas com precisão, já a participante 9 informou que a demanda precisa ser explicada. Por fim, quando questionados se trabalham bem com máquinas, computadores, mapas, horários e outros sistemas, nove dos participantes informaram trabalhar bem. No entanto, dois deles informaram não trabalhar bem com mapas e um informou não trabalhar bem com eletrônicos.

\subsection{Percepção sobre como as competências profissionais específicas podem ser incentiva- das para contribuir para as organizações}

Com relação a percepção dos profissionais sobre como suas competências autísticas podem ser incentivadas para a contribuir para as organizações, a participante 1 descreveu sua atenção aos detalhes, foco, pouca distração e entusiasmo por aprender. As participantes 2 e 7 descreveram atitudes que a empresa poderia tomar para aproveitar suas características com maior qualidade dentro da organização. Em suma foram descritas a valorização e incentivo do hiperfoco. Os participantes 8 e 9 descreveram a realização de uma boa conversa, uma avaliação 
de desempenho ou um direcionamento para outro setor dentro da organização, para que sejam aproveitadas suas características com mais efetividade. A participante 10 destaca que a organização poderia ter um cuidado maior com relação às necessidades especificas dos funcionários. Já a participante 12 ressalta que a organização poderia possibilitar um local com menos estímulos sensoriais, para que ela possa utilizar suas características mais assertivamente. Além disso, ressalta que seria benéfico ao seu desempenho um tempo maior de pausa entre as tarefas.

Dessa maneira, através de ações como avaliações de desempenho e feedbacks a organização poderia compreender as características de cada funcionário e as potencialidades para seu aproveitamento visando o crescimento da organização. Ao questioná-los sobre seus interesses específicos e conhecendo os treinamentos realizados por eles, seria possível estreitar a relação empresa e funcionário. Sendo assim, é importante que as organizações ofereçam oportunidades para efetivar a contratação do profissional autista, através do conhecimento de suas habilidades, da capacitação profissional para seu aprimoramento, de um planejamento adequado de medidas a serem adotadas e uma política empresarial inclusiva.

\section{Considerações Finais}

A pesquisa teve como objetivo entender a percepção do autista sobre como suas competências profissionais específicas podem ser incentivadas para contribuir para as organizações. Tendo em vista suas características específicas relacionadas ao foco nas atividades que são realizadas, atenção aos detalhes, empenho, pouca distração e entusiasmo por aprender, os entrevistados ressaltaram que seria benéfico para a organização a realização de uma conversa ou uma avaliação de desempenho, a fim de compreender o perfil de cada profissional. A partir disso, será possível a estimulação do hiperfoco para fins benéficos às atividades realizadas dentro da empresa ou um direcionamento para outro setor dentro da organização, para que sejam aproveitadas suas características com mais efetividade. Além disso, foi observado a importância de a empresa conhecer as necessidades específicas e características individuais dos funcionários para evitar julgamentos e preconceitos, conhecer os estímulos sensoriais dos funcionários para evitar sobrecargas e realizar adaptações no ambiente de trabalho.

Com relação ao percurso profissional dos entrevistados, é possível afirmar que os participantes buscam se especializar em áreas que possuem interesse. Dentre as barreiras enfrentadas ao ingressar no mercado de trabalho, predominam a dificuldade de socialização dos profissionais e o preconceito dos empregadores. Em atenção às profissões dos participantes, foram identificadas diversas áreas. Dentre os objetivos que auxiliam os funcionários a atingirem seus objetivos, ressaltam-se a liberdade dentro da organização e seus hiperfocos. Como desafios dentro do local de trabalho foram identificadas questões sensoriais relacionadas ao ambiente, disputas de ego entre profissionais, dificuldades em enfrentar mudanças e sensação de incompreensão das pessoas, aliada a dificuldade de compreensão de sinais não-verbais pelos profissionais autistas. Essas situações causam nos profissionais autistas a sensação de exaustão, dificuldade de regulação própria e de detonação.

Os impactos dos interesses específicos nas atividades realizadas pelos profissionais autistas são diversos, como o hiperfoco na carreira, a curiosidade, os estudos e a criatividade. Os interesses causam impactos importantes na vida dos entrevistados, como a possibilidade de autoregulação, independência e a modelagem do comportamento de outras pessoas, possibilitando aprender com seus erros. Com relação às adaptações no ambiente de trabalho, é importante considerar características específicas e singularidades, pois algumas organizações realizaram ajustes à rotina e ao ambiente de trabalho inclusive antes do diagnóstico dos funcionários. Dentre as adaptações, destacam-se a troca de um relógio analógico por um digital, devido ao incomodo causado pelo barulho dos ponteiros, trabalhar em um local mais isolado, sem muito barulho, com uma estação de trabalho própria, possibilidade de se ausentar, carga horária de trabalho reduzida ou flexível, possibilidade de não utilizar o telefone, possibilidade de utilizar os 
fones de ouvido durante o expediente e de ter uma rotina menos rígida. Dentre os benefícios identificados pelos profissionais com as adaptações, é possível destacar a diminuição de distrações, aumento da qualidade do serviço, diminuição da quantidade de crises e da ansiedade no trabalho.

Com relação às situações que distraem os funcionários, evidenciam-se conversas paralelas, brigas, celulares apitando, alarmes, excesso de barulho, sobrecarga por volumes de trabalho ou carga emocional e burocracias que tirem o profissional do foco. Essas situações podem ser amplificadas tendo em vista que pessoas autistas costumam possuir hiper ou hiporreatividade a estímulos sensoriais. Para se recuperar disso, alguns indivíduos levam dias. A maioria dos profissionais autistas entrevistados recebem feedbacks na empresa em que trabalham e sua maioria acredita que são efetivos para a melhora de seu desempenho. No que se refere a relação interpessoal com o superior direto no ambiente de trabalho, destaca-se o acolhimento, tranquilidade, socialização e apoio. Com os demais colegas de trabalho, ressalta-se a dificuldade com relação às interações sociais. Além disso, é importante destacar que os entrevistados possuem facilidade em pedir ajuda com relação às suas tarefas.

Dentre as competências profissionais autísticas, é importante ressaltar capacidade de fazer poucas pausas, ser detalhista, ter empenho, hiperfoco, diciplina com rotinas e regras, concentração, foco e visão diferenciada. Já com relação às características que influenciam negativamente destacam-se impulsividade, ausência de filtros sociais, dificuldades com interações sociais, literalidade e questões sensoriais. Com relação ao padrão disponível na literatura, a maioria dos profissionais consideram sua memória boa, seguem rigorosamente às regras do local de trabalho, pontualidade, trabalham bem com máquinas, computadores, mapas, horários e outros sistemas.

Nessa conjuntura, cabe salientar que um achado importante desta pesquisa e que pode servir de subsídios para outras pesquisas na área é o fato de todos os entrevistados serem do nível 1 de suporte. Ou seja, a principal limitação desta pesquisa foi a dificuldade de encontrar autistas com níveis de suporte 2 e 3 inseridos no mercado de trabalho, de acordo com o DSMV. O que levanta outros questionamentos, tais como se estes também se encontram inseridos no mercado de trabalho tendo em vista que necessitam de maior nível de suporte. Por fim, como sugestões de pesquisas futuras, destaca-se: a) entender a percepção do empregador sobre como as competências profissionais específicas do profissional autista podem contribuir para as organizações; b) compreender as contribuições do empreendedor autista no mercado brasileiro; c) conhecer barreiras laborais para a inclusão do profissional autista no mercado de trabalho; e d) a criação de um manual para auxiliar profissionais do setor de Gestão de Pessoas a fornecer um ambiente de trabalho mais inclusivo ao profissional autista. 


\section{Referências}

AMERICAN PSYCHIATRIC ASSOCIATION. Diagnostic and Statistical Manual of Mental Disorders, 5. ed. (DSM-V). Arlington, VA: APA, 2013.

ARAUJO, J.; SCHMIDT, A. A inclusão de pessoas com necessidades especiais no trabalho: a visão de empresas e de instituições educacionais especiais na cidade de Curitiba. Revista Brasileira de Educação Especial, Marília, v. 12, n. 2, p. 241-254, ago, 2006. DOI: https://doi.org/10.1590/S1413-65382006000200007. Disponível em: https://www.scielo.br/scielo.php?script=sci_arttext\&pid=S1413-65382006000200007\&lng=en\&nrm=iso. Acesso em: 3 set. 2020.

ARMSTRONG, T. Neurodiversity: Discovering the extraordinary gifts of autism, ADHD, dyslexia, and other brain diferences. Cambridge, MA: DaCapo/Perseus Books Group, 2010.

ARMSTRONG, T. Neurodiversity in the classroom: Strength-based strategies to help students with special needs succeed in school and life. Alexandria, VA: Association for Supervision and Curriculum Development, 2012.

AUSTIN, R. D.; SONNE, T. The Dandelion Principle: Redesigning work for the innovation economy. MIT Sloan Management Review, v. 55, n. 4, p. 67-72, 2014. Disponível em: https://sloanreview.mit.edu/article/the-dandelion-principle-redesigning-work-for-the-innovation-economy/. Acesso em: 7 set. 2020.

BOYATZIS, R. E. The competent manager: a model for effective performance. Nova York: John Wiley, 1982.

BARDIN, L. Análise de conteúdo. Lisboa: Edições 70, 1977.

BRASIL. Lei $\mathbf{n}^{\mathbf{0}}$. 8.213, de 24 de julho 1991. Dispõe sobre os planos de benefícios da previdência social e dá outras providências. Diário Oficial da União, seção 1, Brasília, DF, ano 142, p. 14801-14822, 25 jul. 1991. Disponível em: http://www.planalto.gov.br/ccivil_03/leis/18213cons.htm. Acesso em: 18 ago. 2020.

BRASIL. Lei $\mathbf{n}^{\circ}$ 12.764, de 27 de dezembro de 2012. Institui a Política Nacional de Proteção dos Direitos da Pessoa com Transtorno do Espectro Autista. Diário Oficial da União, seção 1, Brasília, DF, ano 250, p. 1-7, 28 dez. 2012. Disponível em: http://www.planalto.gov.br/ccivil_03/_ato2011-2014/2012/lei/112764.htm. Acesso em: 18 ago. 2020.

BRASIL. Lei $\mathbf{n}^{\mathbf{0}}$ 12.764, de 27 de dezembro de 2012. Institui a Política Nacional de Proteção dos Direitos da Pessoa com Transtorno do Espectro Autista. Diário Oficial da União, seção 1, Brasília, DF, ano 250, p. 1-7, 28 dez. 2012. Disponível em: http://www.planalto.gov.br/ccivil_03/_ato2011-2014/2012/lei/112764.htm. Acesso em: 18 ago. 2020.

BRASIL. Lei n⿳ 13.146, de 06 de julho de 2015. Institui a Lei Brasileira de Inclusão da Pessoa com Deficiência (Estatuto da Pessoa com Deficiência). Diário Oficial da União, Brasília, DF, ano 127, p. 1-11, 7 jul. 2015. Disponível em: http://www.planalto.gov.br/ccivil_03/_ato2015-2018/2015/lei/113146.htm. Acesso em: 28 ago. 2020.

BRASIL. Decreto $\mathrm{n}^{\mathbf{0}}$ 9.508, de 24 de setembro de 2018. Reserva às pessoas com deficiência percentual de cargos e de empregos públicos ofertados em concursos públicos e em processos seletivos no âmbito da administração pública federal direta e indireta. Diário Oficial da União, Brasília, DF, ano 185, p. 3-4, 25. set. 2018. Disponível em: http://www.planalto.gov.br/ccivil_03/_ato2015-2018/2018/decreto/d9508.htm. Acesso em: 3 set. 2020.

BRASIL. Ministério da Educação. Instituto Nacional de Estudos e Pesquisas Educacionais Anísio Teixeira. Censo da Educação Superior: Sinopse Estatística da Educação Superior 2018. Brasília: 2019. Disponível em: http://portal.inep.gov.br/web/guest/sinopses-estatisticas-da-educacao-superior. Acesso em: 2 set. 2020.

CARBONE, P. P; BRANDÃO, H. P.; LEITE, J. B. D., VILHENA, R. M. P. Gestão por competências e gestão do conhecimento. 3. ed. Rio de Janeiro: Editora FGV, 2009. 
CHAPPEL, S.; SOMERS, B. Employing persons with autism spectrum disorders: A collaborative effort. Journal Of Vocational Rehabilitation, v. 32, n. 2, p. 117-124, 2010. DOI: http://dx.doi.org/10.3233/jvr-2010-0501. Disponível em: https://content.iospress.com/articles/journal-of-vocational-rehabilitation/jvr501. Acesso em: 8 set. 2020.

CIMERA, R.; COWAN, R. The costs of services and employment outcomes achieved by adults with autism in the US. Autism, v. 13, n. 3, p. 285-302, maio 2009. SAGE Publications and The National Autistic Society. DOI: http://dx.doi.org/10.1177/1362361309103791. Disponível em: https://journals.sagepub.com/doi/abs/10.1177/1362361309103791. Acesso em: 8 set. 2020.

COSTA, B. S.; NAKANDAKARE, E. B.; PAULINO, E. A inserção do autista no meio acadêmico e profissional de tecnologia da informação. Refas-Revista Fatec Zona Sul, v. 4, n. 4, p. 1-10, 2018.

DIAS, A. Por uma genealogia do capacitismo: da eugenia estatal à narrativa capacitista social. Anais do II Simpósio Internacional de Estudos sobre Deficiência. São Paulo, p. 6-14, 2013.

DOS ANJOS, M.; SCHAMKYPOU, B.; DE ALBUQUERQUE, A; MARINHO, G.; BARRETO, J. Pessoa com Deficiência no Mercado de Trabalho e suas Implicações. Id on Line Revista Multidisciplinar e de Psicologia, v. 10, n. 29, p. 51-70, fev. 2016. Disponível em: https://idonline.emnuvens.com.br/id/article/view/384. Acesso em: 8 set. 2020 .

DREAVER, J.; THOMPSON, C.; GIRDLER, S.; ADOLFSSON, M.; BLACK, M. H.; FALKMER, M. Success Factors Enabling Employment for Adults on the Autism Spectrum from Employers' Perspective. Journal of Autism and Developmental Disorders, v. 50, n. 5, p. 1657-1667, 15 fev. 2019. Springer Science and Business Media LLC. DOI: https://doi.org/10.1007/s10803-019-03923-3. Disponível em: https://link.springer.com/article/10.1007\%2Fs10803-019-03923-3. Acesso em: 10 set. 2020.

FLEURY, M. T. L.; FLEURY, A. Construindo o conceito de competência. Rev. adm. contemp., Curitiba, v. 5, n. spe, p. 183-196, 2001. DOI: https://doi.org/10.1590/S1415- 65552001000500010. Disponível em: http://www.scielo.br/scielo.php?script=sci_arttext\&pid=S1415- 65552001000500010\&lng=en\&nrm=iso. Acesso em: 04 set. 2020.

FONSECA, R. T. M da. Direito da Pessoa Portadora de Deficiência. Revista Advocacia Pública \& Sociedade, São Paulo, v. 1, n. 1, p. 135-139, abr. 1997. Max Limonadi.

GARCÍA-VILLAMISAR, D; HUGHES, C. Supported employment improves cognitive performance in adults with Autism. Journal Of Intellectual Disability Research, v. 51, n. 2, p. 142-150, fev. 2007. DOI: https://doi.org/10.1111/j.1365-2788.2006.00854.x. Disponível ht ems://onlinelibrary.wiley.com/doi/abs/10.1111/j.1365-2788.2006.00854.x. Acesso em: 8 set. 2020.

GOMES, P. T. M.; LIMA, L. H. L.; BUENO, M. K. G.; ARAÚJO, L. A.; SOUZA, N. M. Autism in Brazil: a systematic review of family challenges and coping strategies . J. Pediatr. (Rio J.), Porto Alegre, v. 91, n. 2, p. 111-121, Apr. 2015. Elsevier BV. DOI: https://doi.org/10.1016/j.jped.2014.08.009. Disponível em: https://www.scielo.br/scielo.php?script=sci_arttext\&pid=S0021-75572015000200111. Acesso em: 8 set. 2020.

HEDLEY, D.; CAI, R.; ULJAREVIC, M.; WILMOT, M.; SPOOR, J. R.; RICHDALE, A.; DISSANAYAKE, C. Transition to work: perspectives from the autism spectrum. Autism, v. 22, n. 5, p. 528-541, 7 abr. 2017. SAGE Publications. DOI: http://dx.doi.org/10.1177/1362361316687697. Disponível em: https://pubmed.ncbi.nlm.nih.gov/28387577/. Acesso em: 8 set. 2020.

HENDRICKS, D. Employment and adults with autism spectrum disorders: Challenges and strategies for success. Journal Of Vocational Rehabilitation, v. 32, n. 2, p. 125-134, 2010. IOS Press. DOI: http://dx.doi.org/ 10.3233/JVR-2010-0502. Disponível em: https://content.iospress.com/articles/journal-of-vocational-rehabilitation/jvr502. Acesso em: 8 set. 2020.

HILLIER, A.; CAMPBELL, H.; MASTRIANI, K.; IZZO, M. V.; KOOL-TUCKER, A. K.; CHERRY, L.; BEVERSDORF, D. Q. Two-Year Evaluation of a Vocational Support Program for Adults on the Autism Spectrum. Career Development For Exceptional Individuals, v. 30, n. 1, p. 35-47, maio 2007. SAGE Publications. DOI: 
http://dx.doi.org/10.1177/08857288070300010501.

Disponível

em:

https://journals.sage-

pub.com/doi/10.1177/08857288070300010501. Acesso em: 8 set. 2020.

HOWLIN, P. Autism and Asperger syndrome: Preparing for adulthood. 2. ed. Nova York: Routledge, 2004.

HULL, L; PETRIDES, K. V.; ALLISON, C.; SMITH, P.; BARON-COHEN, S.; LAI, M.; MANDY, W. "Putting on My Best Normal": social camouflaging in adults with autism spectrum conditions. Journal Of Autism And Developmental Disorders, v. 47, n. 8, p. 2519-2534, 19 maio 2017. Springer Science and Business Media LLC. DOI: https://doi.org/10.1007/s10803-017-3166-5. Disponível em: https://link.springer.com/article/10.1007/s10803-017-3166-5. Acesso em: 8 set. 2020.

HURLBUTT, K; CHALMERS, L. Employment and adults with Asperger syndrome. Focus on autism and other developmental disabilities, v. 19, n. 4, p. 215-222, 2004. DOI: https://doi.org/10.1177/10883576040190040301. Disponível em: https://journals.sagepub.com/doi/10.1177/10883576040190040301. Acesso em: 8 set. 2020.

KIRBY, A. V.; SCHNEIDER, M.; DIENER, M.; HENDERSON, J. "Who Is Going to Pay for the Wi-Fi?" Exploring Adulthood from the Perspectives of Autistic Youth. Autism In Adulthood, v. 1, n. 1, p. 37-43, 2019. DOI: https://doi.org/10.1089/aut.2018.0008. Disponível em: https://www.liebertpub.com/doi/full/10.1089/aut.2018.0008. Acesso em: 25 jul. 2021.

KLIN, A. Autismo e síndrome de Asperger: uma visão geral. Revista Brasileira de Psiquiatria, v. 28, n. 1, p. 3 11, maio 2006. DOI: http://dx.doi.org/10.1590/s1516-44462006000500002. Disponível em: https://www.scielo.br/scielo.php?script=sci_arttext\&pid=S1516-44462006000500002\&lng=pt\&tlng=pt. Acesso em: 8 set. 2020 .

LATTIMORE, L. P.; PARSONS, M. B.; REID, D. H. Assessing preferred work among adults with autism beginning supported jobs: identification of constant and alternating task preferences. Behavioral Interventions, v. 18, n. 3, p. 161-177, 21 jun. 2003. Wiley. DOI: https://doi.org/10.1002/bin.138. Disponível em: https://onlinelibrary.wiley.com/doi/abs/10.1002/bin.138. Acesso em: 8 set. 2020.

LAVILLE, C.; DIONNE, J. A construção do saber. Belo Horizonte: UFMG, 1999.

LEOPOLDINO, C. B. Inclusão de autistas no mercado de trabalho: Uma nova questão de pesquisa para os brasileiros. Gestão e Sociedade, v. 9, n. 22, p. 853-868, 2015. DOI: https://doi.org/10.21171/ges.v9i22.2033. Disponível em: https://www.gestaoesociedade.org/gestaoesociedade/article/view/2033. Acesso em: 10 set. 2020.

LEOPOLDINO, C. B.; COELHO, P. F. C. O Processo de Inclusão de Autistas no Mercado de Trabalho. Revista Economia \& Gestão, v. $17, \quad$ n. 48 , p. 141-156, 2017. DOI: http://dx.doi.org/10.5752/P.19846606.2017v17n48p141-156. Disponível em: http://periodicos.pucminas.br/index.php/economiaegestao/article/view/15660. Acesso em: 8 set. 2020.

LEOPOLDINO, C. B.; DA SILVA FILHO, J. C. L.; NISSEL, K. M. Inclusão Produtiva de Pessoas com Autismo: o Caso da Auticon. Revista Interdisciplinar de Gestão Social, v. 9, n. 3, p. 15-33, 2020.

LIU, X.; TAKUMI, T. Genomic and genetic aspects of autism spectrum disorder. Biochemical and Biophysical Research Communications, v. 452, n. 2, p. 244-253, set. 2014. Elsevier BV. DOI: https://doi.org/10.1016/j.bbrc.2014.08.108. Disponível em: https://www.sciencedirect.com/science/article/abs/pii/S0006291X1401540X?via\%3Dihub. Acesso em: 18 ago. 2020.

LOVAAS, O. I.; SCHREIBMAN, L.; KOEGEL, R.; REHM, R. Selective responding by autistic children to multiple sensory input. Journal of Abnormal Psychology, v. 77, n. 3, p. 211-222, 1971. DOI: https://doi.org/10.1037/h0031015. Disponível em: https://doi.apa.org/doiLanding?doi=10.1037\%2Fh0031015. Acesso em: 10 set. 2020.

LOWINGER, S.; PEARLMAN-AVNION, S. Autism in Adulthood. Autism and child psychopathology series. Cham: Springer, 2019. 
LUNG, W. S.; RICCO, A. S. Gêneros e identidades: estigma e preconceito na percepção de estudantes universitários. DESTARTE, v. 7, n. 1, p. 26-47, 2017.

MALUF, R. T. Gestão de pessoas e o setor público. São Paulo, 2009, revisto e alterado em agosto de 2014. Disponível em: http://www.processoedecisao.com.br/ART- TextBasico2014.pdf. Acesso em: 5 set. 2020.

MAWHOOD, L.; HOWLIN, P. The Outcome of a Supported Employment Scheme for High-Functioning Adults with Autism or Asperger Syndrome. Autism, [S.L.], v. 3, n. 3, p. 229-254, set. 1999. SAGE Publications. DOI: http://doi.org/10.1177/1362361399003003003.

MCSTAY, R. L; DISSANAYAKE, C.; SCHEEREN, A.; KOOT, H. M; BEGEER, S. Parenting stress and autism: the role of age, autism severity, quality of life and problem behaviour of children and adolescents with autism. Autism, v. 18, n. 5, p. 502-510, 8 out. 2013. SAGE Publications. DOI: https://doi.org/10.1177/1362361313485163. Disponível em: https://journals.sagepub.com/doi/10.1177/1362361313485163. Acesso em: 8 set. 2020.

ORSMOND, G. I.; SHATTUCK, P. T.; COOPER, B. P.; STERZING, P. R.; ANDERSON, K. A. Social participation among young adults with an autism spectrum disorder. Journal Of Autism And Developmental Disorders, v. 43, n. 11, p. 2710-2719, 25 abr. 2013. Springer Science and Business Media LLC. DOI: https://doi.org/10.1007/s10803-013-1833-8. Disponível em: https://link.springer.com/article/10.1007\%2Fs10803013-1833-8. Acesso em: 8 set. 2020

PARR, A. D.; HUNTER, S. T. Enhancing work outcomes of employees with autism spectrum disorder through leadership: leadership for employees with autism spectrum disorder. Autism, v. 18, n. 5, p. 545-554, 25 jul. 2013. DOI: https://doi.org/10.1177/1362361313483020. Disponível em: https://journals.sagepub.com/doi/10.1177/1362361313483020. Acesso em: 8 set. 2020.

PARRY, S. B. The quest for competencies. Training, v. 33, n. 7, p. 48-56, jul. 1996.

RAPPAPORT, J. Terms of empowerment/exemplars of prevention: toward a theory for community psychology. American Journal of Community Psychology, v. 15, n. 2, p. 121-148, 1 abr. 1987. Wiley. DOI: https://doi.org/10.1007/BF00919275. Disponível em: https://onlinelibrary.wiley.com/doi/abs/10.1007/BF00919275. Acesso em: 8 set. 2020.

ROSA, M. V. de F. P. C.; ARNOLDI, M. A. G. C. A Entrevista na pesquisa qualitativa: mecanismo para validação dos resultados. Belo Horizonte: Autêntica, 2006.

ROSQVIST, H. B.; KEISU, B. Adaptation or recognition of the autistic subject? Reimagining autistic work life: Deconstructing the notion of "real jobs" in the Swedish autistic self-advocacy movement. Journal of Vocational Rehabilitation, v. 37, n. 3, p. 203-212, 2012. IOS Press. DOI: http://doi.org/10.3233/JVR-2012-0615. Disponível em: https://content.iospress.com/articles/journal-of-vocational-rehabilitation/jvr615. Acesso em: 8 set. 2020.

ROUX, A. M; SHATTUCK, P. T.; COOPER, B. P.; ANDERSON, K. A.; WAGNER M.; NARENDORF, S. C. Postsecondary employment experiences among young adults with an autism spectrum disorder. Journal of the American Academy OF Child \& Adolescent Psychiatry, v. 52, n. 9, p. 931-939, 1 set. 2013. DOI: http://doi.org/10.1016/j.jaac.2013.05.019. Disponível em: https://jaacap.org/article/S0890-8567(13)00377-8/fulltext. Acesso em: 8 set. 2020.

SALES, J. F.; VIANA, T. V. A inclusão de autistas no ensino superior: direito, acessibilidade e avaliação. Revista Intersaberes, v. 15, n. 35, 2020. Disponível em: https://www.uninter.com/intersaberes/index.php/revista/article/view/1868. Acesso em: 2 set. 2020.

SASSAKI, R. K. Inclusão: construindo uma sociedade para todos. Rio de Janeiro: WVA, 1997.

SCHALL, C. M. Positive behavior support: supporting adults with autism spectrum disorders in the workplace. Journal Of Vocational Rehabilitation, v. 32, n. 2, p. 109-115, 2010. IOS Press. DOI: http://doi.org/10.3233/JVR2010-0500. Disponível em: https://content.iospress.com/articles/journal-of-vocational-rehabilitation/jvr500. Acesso em: 8 set. 2020. 
SCHALL, C.; WEHMAN, P.; MCDONOUGH, J. L. Transition from school to work for students with autism spectrum disorders: understanding the process and achieving better outcomes. Pediatric Clinics of North America, v. 59, n. 1, p. 189-202, fev. 2012. DOI: http://doi.org/10.1016/j.pcl.2011.10.009. Disponível em: https://www.sciencedirect.com/science/article/abs/pii/S0031395511001441?via\%3Dihub. Acesso em: 8 set. 2020.

SEAMAN, R. L.; CANNELLA-MALONE, H. I. Vocational Skills Interventions for Adults with Autism Spectrum Disorder: a review of the literature. Journal Of Developmental And Physical Disabilities, v. 28, n. 3, p. 479494, 2 mar. 2016. Springer Science and Business Media LLC. DOI: http://doi.org/10.1007/s10882-016-9479-z.

SEVERINO, A. J. Metodologia do trabalho científico. 23. ed. rev. e atual. São Paulo: Cortez, 2007.

VERGARA, S. C. Métodos de Pesquisa em Administração. São Paulo: Atlas, 2005.

VIEIRA, M. M. F.; ZOUAIN, D. M. Pesquisa qualitativa em administração. Rio de Janeiro: FGV, 2004.

VILAS BOAS, A. A.; ANDRADE, R. O. B. Gestão estratégica de pessoas. Rio de Janeiro: Elsevier, 2009.

WAREHAM, J.; SONNE, T. Harnessing the power of autism spectrum disorder. Innovations: Technology, Governance, Globalization, v. 3, n. 1, p. 11-27, 2008. DOI: http://doi.org/10.1162/itgg.2008.3.1.11. Disponível em: https://www.mitpressjournals.org/doi/10.1162/itgg.2008.3.1.11. Acesso em: 8 set. 2020.

WEHMAN, P.; LAU, S.; MOLINELLI, A.; BROOKE, V.; THOMPSON, K.; MOORE, C.; WEST, M. Supported Employment for Young Adults with Autism Spectrum Disorder: preliminary data. Research And Practice For Persons With Severe Disabilities, v. 37, n. 3, p. 160-169, 2012. SAGE Publications. DOI: http://doi.org/10.2511/027494812804153606. Disponível em: https://journals.sagepub.com/doi/10.2511/027494812804153606. Acesso em: 8 set. 2020.

WING, L. El Autismo em niños y adultos: una guía para la família. Buenos Aires: Aique, 1998.

WINTER-MESSIERS, M. A.; HERR, C. M.; WOOD, C. E.; BROOKS, A. P.; GATES, M. A. M.; HOUSTON, T. L.; TINGSTAD, K. I. How Far Can Brian Ride the Daylight 4449 Expresse? A Strength-Based Model of Asperger Syndrome Based on Special Interest Areas. Focus on Autism and Other Development Disabilities, v. 22, n. 2, p. 67-79, 2007. DOI: https://doi.org/10.1177/10883576070220020701. Disponível em: https://journals.sagepub.com/doi/10.1177/10883576070220020701. Acesso em: 8 set. 2020.

WORLD HEALTH ORGANIZATION. The ICD-10 classification of mental and behavioral disorders. Clinical descriptions and diagnostic guidelines. Geneva: WHO, 1992. 


\section{APÊNDICE - Roteiro semi-estruturado}

1) Perguntas para caracterização dos entrevistados:

a) Qual sua idade e seu gênero?

b) Qual a sua cidade e estado de residência?

c) Qual a sua escolaridade? Em caso de ensino superior, qual o curso?

d) Você possui diagnóstico formal de autismo? Possui outras comorbidades diagnosticadas? Se sim, quais?

e) Com quantos anos você obteve seu diagnóstico no espectro autista? É possível informar o seu nível de suporte de acordo com o DSM-V?

f) Como foi para você descobrir que está no espectro autista? O que mudou em sua identificação individual?

g) Quais profissionais foram responsáveis por esse diagnóstico?

2) Perguntas para compreensão do percurso profissional:

a) Você teve alguma preparação para a atuação profissional? Por exemplo, ensino técnico, cursos profissionalizantes etc.

b) Quais barreiras enfrentadas até entrar no mercado de trabalho?

c) Ao procurar emprego, você informa que é autista? Em caso positivo, já sofreu algum tipo de preconceito por isso? Poderia descrever a situação?

d) Como você encontrou este emprego?

e) Você entrou por meio da Lei de Cotas na empresa atual?

f) A empresa que você trabalha sabe do seu diagnóstico? E seus colegas de trabalho?

g) Caso você não tenha divulgado seu diagnóstico, qual foi o motivo?

h) Você sente que possui possibilidade de crescimento profissional na empresa em que trabalha?

i) Qual a carga horária semanal do seu emprego?

3) Perguntas para descrição da rotina de trabalho:

a) Qual o ramo/setor da empresa que você trabalha? E a área de atuação?

b) Você saberia dizer o porte da empresa (pequeno, médio ou grande)?

c) Qual é o seu cargo atual?

d) Há quanto tempo você trabalha lá?

e) Você trabalha com outras pessoas autistas ou com outras deficiências?

f) Pensando em seu cargo atual, quais são as características que te ajudaram a atingir seus objetivos no trabalho?

g) O que foi mais difícil ou desafiador para você no local de trabalho até hoje?

4) Perguntas sobre o impacto dos interesses específicos no ambiente de trabalho:

a) Você possui interesses específicos? Caso positivo, quais? Eles se relacionam de alguma forma com as atividades que você executa em seu emprego atual? 
b) Você saberia descrever alguns benefícios de seus interesses específicos em sua vida?

5) Perguntas sobre adaptações do ambiente de trabalho:

a) A organização que você trabalha realizou alguma adaptação no ambiente ou na rotina de trabalho para você? Em caso positivo, quais? Em caso negativo, o que você acha que poderia ser feito para facilitar esse processo?

b) Caso a resposta acima tenha sido positiva, você acredita que essas adaptações causam em você lealdade à empresa?

c) Qual a influência das adaptações na qualidade do seu serviço?

d) O que distrai você no seu ambiente de trabalho? Como você lida com isso? Quanto tempo leva para se recuperar disso?

e) Seus superiores realizam feedbacks com você? Em caso positivo, são efetivos para melhorar seu desempenho?

6) Perguntas sobre a relação interpessoal no ambiente de trabalho:

a) Poderia descrever sobre a sua relação com o seu superior direto, especificando sobre a socialização, os desafios, as dificuldades e os pontos positivos? Ele te apoia em suas tarefas? Se sim, como?

b) Poderia descrever sobre a sua relação com os demais colegas de trabalho, especificando sobre a socialização, os desafios, as dificuldades e as coisas boas? Ele te apoia em suas tarefas? Se sim, como?

c) Você costuma se distrair com chamadas em seu celular ou com a utilização de redes sociais durante o expediente de trabalho?

d) Você costuma ter conversas paralelas com seus colegas de trabalho durante o expediente?

e) Possui facilidade para pedir ajuda quando não consegue compreender algo sobre suas tarefas?

7) Perguntas sobre a percepção das competências profissionais com base em suas características pessoais e específicas de indivíduos no espetro autista:

a) Você acredita que possua características especificas do autismo que agregam seu desempenho em seu emprego? Em caso positivo, quais?

b) Você acredita que possua características especificas do autismo que influenciam negativamente seu desempenho em seu emprego? Em caso positivo, quais?

c) Você acredita que suas competências características do autismo estão sendo bem aproveitadas em seu cargo atual?

8) Perguntas para comparar com o padrão disponível na literatura sobre competências profissionais com base em características pessoais e específicas de indivíduos no espetro autista:

a) Em seu local de trabalho, ao realizar suas tarefas, você se considera concentrado?

b) Você considera sua memória boa?

c) Você acha que possui bom senso de observação? 
d) Você acha que possui facilidade em autocorreção?

e) Você acha que possui uma forte atenção para detalhes?

f) Você possui interesse por tarefas repetitivas e que demandem foco?

g) Você costuma completar todas as atividades que lhe são demandadas?

h) Você prefere que suas tarefas sejam repassadas para você de forma escrita ou falada?

i) Em seu local de trabalho, você segue rigorosamente às regras?

j) Você gosta de ter uma rotina em seu ambiente de trabalho?

k) Você se considera assíduo e pontual?

1) Você prefere ambientes visualmente organizados ou é indiferente?

m) Você trabalha bem com máquinas, computadores, mapas, horários e outros sistemas?

n) Você acredita que realiza suas tarefas com precisão?

9) Qual a sua percepção sobre como suas competências profissionais específicas podem ser incentivadas para contribuir para sua empresa? 